\title{
Lactobacillus plantarum PS128 prevents cognitive dysfunction in Alzheimer's disease mice by modulating propionic acid levels, glycogen synthase kinase 3 beta activity, and gliosis
}

Hei-Jen Huang ${ }^{1}$, Jie-Ling Chen², Jian-Fu Liao ${ }^{3}$, Yu-Hsin Chen ${ }^{1}$, Min-Wei Chieu' ${ }^{1}$ Ya-Yun Ke², Chih-Chieh Hsu ${ }^{4}$, Ying-Chieh Tsai ${ }^{3^{*}}$ and Hsiu Mei Hsieh-Li ${ }^{2^{*}}$ (1)

\begin{abstract}
Background: According to recent evidence, psychobiotics exert beneficial effects on central nervous system-related diseases, such as mental disorders. Lactobacillus plantarum PS128 (PS128), a novel psychobiotic strain, improves motor function, depression, and anxiety behaviors. However, the psychobiotic effects and mechanisms of PS128 in Alzheimer's disease (AD) remain to be explored.

Objectives: The goal of the current study was to evaluate the beneficial effects of PS128 and to further elucidate its mechanism in AD mice.

Methods: PS128 (10 10 colony-forming unit (CFU)/ml) was administered via oral gavage (o.g.) to 6-month-old male wild-type B6 and $3 \times \mathrm{Tg}$-AD mice (harboring the PS1M146V, APPswe and TauP30IL transgenes) that received an intracerebroventricular injection of streptozotocin (icv-STZ, $3 \mathrm{mg} / \mathrm{kg}$ ) or vehicle (saline) for 33 days. After serial behavioral tests, fecal short-chain fatty acid levels and AD-related pathology were assessed in these mice.

Results: Our findings show that intracerebroventricular injection of streptozotocin accelerated cognitive dysfunction associated with increasing levels of glycogen synthase kinase 3 beta (GSK3 $\beta$ ) activity, tau protein phosphorylation at the T231 site (pT231), amyloid- $\beta$ (A $\beta$ ) deposition, amyloid- $\beta$ protein precursor (A $\beta P P)$, $\beta$-site A $\beta P P$-cleaving enzyme (BACE1), gliosis, fecal propionic acid (PPA) levels and cognition-related neuronal loss and decreasing postsynaptic density protein 95 (PSD95) levels in $3 \times$ Tg-AD mice. PS128 supplementation effectively prevented the damage induced by intracerebroventricular injection of streptozotocin in $3 \times \mathrm{Tg}-\mathrm{AD}$ mice.
\end{abstract}

Conclusions: Based on the experimental results, intracerebroventricular injection of streptozotocin accelerates the progression of $A D$ in the $3 \times \mathrm{Tg}-\mathrm{AD}$ mice, primarily by increasing the levels of gliosis, which were mediated by the

\footnotetext{
*Correspondence: tsaiyc@ym.edu.tw; hmhsieh@ntnu.edu.tw

2 Department of Life Science, National Taiwan Normal University,

Taipei 11677, Taiwan

${ }^{3}$ Institute of Biochemistry and Molecular Biology, National Yang Ming

Chiao Tung University, Taipei 11221, Taiwan

Full list of author information is available at the end of the article
}

(c) The Author(s) 2021, corrected publication 2022. Open Access This article is licensed under a Creative Commons Attribution 4.0 International License, which permits use, sharing, adaptation, distribution and reproduction in any medium or format, as long as you give appropriate credit to the original author(s) and the source, provide a link to the Creative Commons licence, and indicate if changes were made. The images or other third party material in this article are included in the article's Creative Commons licence, unless indicated otherwise in a credit line to the material. If material is not included in the article's Creative Commons licence and your intended use is not permitted by statutory regulation or exceeds the permitted use, you will need to obtain permission directly from the copyright holder. To view a copy of this licence, visit http://creativecommons.org/licenses/by/4.0/. The Creative Commons Public Domain Dedication waiver (http://creativecommons.org/publicdomain/zero/1.0/) applies to the data made available in this article, unless otherwise stated in a credit line to the data. 
propionic acid and glycogen synthase kinase 3 beta pathways. PS128 supplementation prevents damage induced by intracerebroventricular injection of streptozotocin by regulating the propionic acid levels, glycogen synthase kinase 3 beta activity, and gliosis in $3 \times \mathrm{Tg}$-AD mice. Therefore, we suggest that PS128 supplementation is a potential strategy to prevent and/or delay the progression of AD.

Keywords: PS128 psychobiotic, Streptozotocin, Propionic acid, Gliosis, Glycogen synthase kinase 3 beta, Cognition

\section{Background}

Alzheimer's disease (AD) is characterized by progressive and irreversible memory loss that results in a substantial burden on the patient and caregivers. The pathological features of AD include the progressive accumulation of parenchymal senile plaques consisting of amyloid- $\beta$ $(\mathrm{A} \beta)$ protein and intracellular neurofibrillary tangles (NFTs) composed of abnormal phosphorylated tau, which induce chronic gliosis primarily in cognitive brain areas, and subsequently lead to synaptic damage, cognitive impairment, and neurodegeneration [1-3]. However, the multifactorial nature of $\mathrm{AD}$ makes the treatment of AD challenging [4]. To date, anti-amyloid and anti-tau agents have not been successful in clearing or preventing AD pathology [5]. Therefore, an urgent need is to develop viable therapeutics and preventive treatments to improve the quality of life of patients with $\mathrm{AD}$ and to decrease the burden of caregivers.

The decreased diversity of the gut microbiota in patients with AD has attracted interest in recent years [6-8]. The term "microbiota-gut-brain axis" has also been used to describe the association between gut microbiota and $\mathrm{AD}$ through various routes, including the immune system, tryptophan metabolism, microbial metabolites, the vagus nerve and the enteric nervous system [7]. Evidence suggests that short-chain fatty acids (SCFAs), including butyric acid (C4), propionic acid (C3), acetic acid (C2), and microbial metabolites in the colon, attenuate the neuropathological features of $\mathrm{AD}$ and other neurodegenerative diseases by providing an alternative energy source to rectify brain hypometabolism [9]. Additionally, selected SCFAs might modulate neuroinflammation, which is a major pathomechanism of the early and preclinical course of AD [10,11]. Based on accumulating evidence, long-term dietary supplementation with probiotics containing multiple strains improves cognitive dysfunction in individuals with AD [12, 13]. Lactobacillus plantarum MTCC1325 and Lactobacillus pentosus var. plantarum (C29) were also shown to attenuate memory impairment in D-galactose-induced AD animal models $[14,15]$. The reports described above suggest that probiotic supplementation may be an effective method to delay AD progression. L. plantarum PS128 (PS128) is a psychobiotic isolated from fu-tsai, a traditional Taiwanese fermented vegetable food product that has been reported to reduce anxiety and depression by decreasing inflammation and cortisol levels [16, 17]. Recent evidence also suggests that PS128 psychobiotics attenuate hyperactive behaviors by modulating the microbiota-gut-brain axis [18]. However, the relationship between SCFAs derived from microbial metabolites and PS128 psychobiotics in individuals with $\mathrm{AD}$ remains unclear.

An intricate relationship exists between the gut microbiota and the development of types 1,2 and 3 diabetes [19]. Type 3 diabetes has been proposed as a common term for $\mathrm{AD}$ [20]. The impairment of brain glucose uptake/metabolism is a common early abnormality in individuals with $\mathrm{AD}$ [21]. Accumulating evidence also reveals an important role for brain glucose hypometabolism in the process of cognitive decline and aging [22-25]. An intracerebroventricular injection of the diabetogenic toxin streptozotocin (icv-STZ) exacerbates memory disturbances and AD-like neurochemical changes in the brains of $3 \times \mathrm{Tg}$ - $\mathrm{AD}$ mice (harboring the PS1M146V, APPswe and TauP30IL transgenes) by impairing insulin signaling $[26,27]$. Therefore, icv-STZ was used to accelerate $\mathrm{AD}$ progression in 6-month-old male $3 \times \mathrm{Tg}$-AD mice (the age before typical AD pathologies develop) in the present study. We aim to examine the beneficial effects of PS128 on $3 \times \mathrm{Tg}$-AD mice treated with icv-STZ and to elucidate the role of SCFAs in $3 \times \mathrm{Tg}$-AD mice treated with PS128 and icv-STZ. Our results showed that the administration of icv-STZ accelerated the disease progression of $\mathrm{AD}$, which might result from gliosis occurring through increased GSK $3 \beta$ activity and fecal PPA levels in $3 \times$ Tg-AD mice. PS128 supplementation effectively prevented the damage induced by icv-STZ by reducing the fecal PPA levels, GSK3 $\beta$ activity, and gliosis in $3 \times \mathrm{Tg}-\mathrm{AD}$ mice.

\section{Methods \\ Animals}

C57BL/6 J male mice and $3 \times \mathrm{Tg}-\mathrm{AD}$ mice on a B6/129 hybrid genetic background were purchased from the National Breeding Center for Laboratory Animals and Jackson Laboratory (004807; Bar Harbor, ME, USA). $3 \times \mathrm{Tg}-\mathrm{AD}$ mice were backcrossed for more than 10 generations to the B6 background. Based on our previous results, we did not detect an obvious cognitive impairment or other typical pathological features in the 
$3 \times \mathrm{Tg}$-AD male mice at 6 to 7 months of age [28]. Therefore, bilateral icv-STZ was used to exacerbate the progression of $\mathrm{AD}$, as described in previous studies [26, 27]. The mice were housed at $20-25^{\circ} \mathrm{C}$ with $50-60 \%$ relative humidity on a $12 \mathrm{~h} \mathrm{light/dark}$ cycle, and food and water were available ad libitum. The body weight of mice was approximately $26-27 \mathrm{~g}$. All experiments were performed during the light phase between 7:00 a.m. and 7:00 p.m. To minimize animal suffering, the mice were deeply anesthetized with avertin $(0.4 \mathrm{~g} / \mathrm{kg}$ body weight, Sigma; St. Louis, MO, USA) and then sacrificed by perfusion or cervical dislocation for pathological analyses after a series of behavioral tasks. All experimental procedures were approved by an ethics committee at the Institutional Animal Care and Use Committee (IACUC) of National Taiwan Normal University (Permit Number: 106036).

\section{Experimental design}

The experimental timeline is shown in Fig. S1A. Wildtype $\mathrm{B} 6$ and $3 \times \mathrm{Tg}$ - $\mathrm{AD}$ mice aged 6 months were randomly divided into 6 groups (15-20 mice/group) according to the sigmoid distribution of body weight: (i) B6 mice treated with saline (oral gavage, o.g.)/saline (icv) as control group; (ii) B6 mice treated with PS128 (o.g.)/saline (icv); (iii) $3 \times$ Tg-AD mice treated with saline (o.g.)/saline (icv); (iv) $3 \times \mathrm{Tg}$-AD mice treated with PS128 (o.g.)/saline (icv); (v) $3 \times \mathrm{Tg}$-AD mice treated with saline (o.g.)/STZ (icv); and (vi) $3 \times \mathrm{Tg}$-AD mice treated with PS128 (o.g.)/STZ (icv). After adaption to handling and o.g. for 7 days (days 8-14), the mice were administered $100 \mu \mathrm{L}$ of PS128 (o.g., daily, $10^{10} \mathrm{CFU} / \mathrm{ml}$; Bened Biomedical; Taipei, Taiwan) or the saline vehicle for 33 days (days 8-41). The concentration of PS128 was selected according to previous studies [16, 17]. Seven days after PS128 administration, the mice were anesthetized with avertin $(0.4 \mathrm{~g} / \mathrm{kg}$ of body weight; Sigma $)$ and received a single icv injection of $2 \mu \mathrm{L}$ of STZ ( $3 \mathrm{mg} / \mathrm{kg}$; Sigma) or vehicle (saline) into the bilateral ventricle $(0.3 \mathrm{~mm}$ with respect to the bregma, $1.0 \mathrm{~mm}$ right and left of the central suture, $2.5 \mathrm{~mm}$ deep). Serial behavioral tests, namely, the open field test (OFT), elevated plus maze (EPM), Y maze and Morris water maze (MWM), were conducted on days $22-23,26-27,28-29$, and 34-40, respectively. Finally, the mice were sacrificed for western blot, immunohistochemical, and SCFA analyses of fecal boli on day 41. Before sacrifice, mouse blood samples were obtained by a tail prick to measure glucose levels using a commercial glucometer (Accu-CheckActive; Roche, Mannheim, Germany).

\section{Behavioral assessments}

Mice were subjected to a series of behavioral tasks ( $n=15-20 /$ group). All mice were habituated in the behavioral room for $30 \mathrm{~min}$ before testing, and all behavioral apparatuses were carefully cleaned between subjects with 70 and $30 \%$ ethanol sequentially to remove any olfactory cues. Behavioral data were recorded using a video camera and analyzed using an automatic tracking system (EthoVision-XT; Noldus, Wageningen, The Netherlands).

\section{Open field test (OFT)}

The OFT was conducted using a recently described method [29]. Briefly, mice were individually placed in the central zone $(15 \times 15 \mathrm{~cm})$ of a white acrylic box $(30 \mathrm{~cm}$ long $\times 30 \mathrm{~cm}$ wide $\times 30 \mathrm{~cm}$ high) and then recorded for $10 \mathrm{~min}$. The total distance travelled by the mice was measured as an index of exploratory activity, and a decrease in the time spent in the center of the open field arena was considered an index of anxiety-like phenotypes.

\section{Elevated plus maze (EPM)}

The EPM was carried out as described in a recent study [29]. The EPM apparatus consisted of a plus-shaped maze constructed of white opaque acrylic with two opposing open arms ( $30 \mathrm{~cm}$ long $\times 5 \mathrm{~cm}$ wide) and two opposing closed arms $(30 \mathrm{~cm}$ long $\times 5 \mathrm{~cm}$ wide $\times 15 \mathrm{~cm}$ high) connected by a central platform $(10 \mathrm{~cm}$ long $\times 10 \mathrm{~cm}$ wide) and elevated $50 \mathrm{~cm}$ above the floor. The mouse was placed in the central zone with its head directed toward an open arm and allowed to explore the maze for $5 \mathrm{~min}$. The time spent in the open arms was recorded with a camera and considered an index of an anxiolytic effect.

\section{Y maze}

The $\mathrm{Y}$ maze testing procedure was performed as previously reported [27]. The Y maze apparatus consisted of 3 identical symmetrical arms $(46 \mathrm{~cm}$ long $\times 3 \mathrm{~cm}$ wide $\times 17 \mathrm{~cm}$ high) with white acrylic walls. During an $8 \mathrm{~min}$ test session, each mouse was initially placed in the central space and allowed to freely explore in the Y maze. Arm entry was defined as the entry of all four paws into one arm. The spontaneous alternation percentage, an indicator of short-term memory, was calculated using the following equation: [the number of sequential triplets containing entries in the three arms/(total arm entries $-2) \times 100]$.

\section{Morris water maze (MWM)}

The MWM task was used to evaluate the spatial learning and memory abilities of mice as previously described [29]. The MWM assay consisted of four stages: pretraining (day 34), training (days 35-38), testing (day 39), and probe (day 40). The swimming ability of the mice was tested on day 34. Mice that floated in the pool were not included in the task. The MWM consisted of a large 
circular white pool $(100 \mathrm{~cm}$ in diameter and $47 \mathrm{~cm}$ in height) filled with water $\left(21 \pm 2^{\circ} \mathrm{C}\right)$ and divided into four quadrants. A hidden platform with a diameter of $10 \mathrm{~cm}$ was located $1 \mathrm{~cm}$ below the water level in the center of the target quadrant in the pool during the pretraining, training, and testing periods. The time to climb onto the hidden platform within $60 \mathrm{~s}$ was recorded as the escape latency. During days 35-38, mice were trained four times per day and allowed to rest for $15 \mathrm{~min}$ between trials. The mouse was allowed to search for the platform for $60 \mathrm{~s}$ and was allowed to remain on the platform for $20 \mathrm{~s}$. If a mouse did not find the platform within $60 \mathrm{~s}$, it was gently guided to the platform, where it remained for $20 \mathrm{~s}$, and the escape latency was recorded as $60 \mathrm{~s}$. The training curve from days 35 to 38 was recognized as an index of spatial learning ability. On day 39 (testing), three testing trials were conducted as an index of spatial learning acquisition. Twenty-four hours after the last testing trial, a probe test (day 40, two trials) was performed by removing the platform and allowing each mouse to swim freely for $60 \mathrm{~s}$ in the pool. The amount of time spent in the target quadrant was calculated as an index of long-term spatial memory.

\section{Analysis of fecal short chain fatty acid (SCFA) contents}

Before sacrifice (on day 41), fresh feces $(100 \mathrm{mg}$ ) were collected from individual mice ( $n=5 /$ group) and suspended in $1 \mathrm{ml}$ of $0.5 \%$ phosphoric acid with $200 \mathrm{ppm}$ 2-ethylbutyric acid as a surrogate standard. The fecal suspensions were homogenized by vortexing for $2 \mathrm{~min}$ and centrifuging for $10 \mathrm{~min}$ at $17000 \times \mathrm{g}$. The supernatant was extracted with an equal volume of ethyl acetate by vortexing for $10 \mathrm{~min}$ and centrifuging for $10 \mathrm{~min}$ at $17000 \times \mathrm{g}$. The organic extracts were stored at $-80^{\circ} \mathrm{C}$ before analysis [30]. Prior to analysis, $600 \mu \mathrm{L}$ of the organic extracts were transferred into a sample vial, and 4-methyl valeric acid was added as an internal standard at a final concentration of $200 \mathrm{ppm}$. A GC-MS analysis was performed using an Agilent $6890 \mathrm{~N}$ GC system equipped with an Agilent 5973 N mass detector (Agilent; Wilmington, Delaware, USA). A fused-silica capillary column DB-FFAP (30 $\mathrm{m}$ length, $0.25 \mathrm{~mm}$ inner diameter, $0.25 \mu \mathrm{m}$ film thickness, J\&W Scientific, Agilent) was used. Helium was supplied as the carrier gas at a rate of $1 \mathrm{ml} / \mathrm{min}$. The injection was performed in splitless mode with an injection volume of $1 \mu \mathrm{L}$ and an injector temperature of $250^{\circ} \mathrm{C}$. The initial oven temperature was maintained at $80^{\circ} \mathrm{C}$ for $1 \mathrm{~min}$, increased to $100^{\circ} \mathrm{C}$ at $4^{\circ} \mathrm{C} / \mathrm{min}$, maintained at $100^{\circ} \mathrm{C}$ for $1 \mathrm{~min}$, increased to $180^{\circ} \mathrm{C}$ at $8^{\circ} \mathrm{C} / \mathrm{min}$, maintained at $180^{\circ} \mathrm{C}$ for $1 \mathrm{~min}$, increased to $220^{\circ} \mathrm{C}$ at $20^{\circ} \mathrm{C} /$ min, and finally held at $220^{\circ} \mathrm{C}$ for $5 \mathrm{~min}$. The temperatures of the ion source, quadrupole, and interface were $230^{\circ} \mathrm{C}, 150^{\circ} \mathrm{C}$, and $280^{\circ} \mathrm{C}$, respectively. The detector was operated in electron impact ionization mode (electron energy, $70 \mathrm{eV}$ ), scanning the $35-250 \mathrm{~m} / \mathrm{z}$ range. The solvent delay was $3.5 \mathrm{~min}$. SCFA mixtures consisting of acetic acid, propionic acid, and butyric acid were prepared at a series of concentrations $(10,20,50,100,200,300$ and $400 \mathrm{ppm}$ ) with a $200 \mathrm{ppm}$ internal standard to construct the calibration curves. The concentration of SCFAs was calculated from the internal standard curve.

\section{Immunohistochemistry (IHC)}

Mice ( $n=3$ /group) were transcardially perfused with saline followed by $4 \%$ paraformaldehyde in $0.1 \mathrm{M}$ phosphate buffer ( $\mathrm{pH}$ 7.4) under deep anesthesia induced by an intraperitoneal injection of avertin $(0.4 \mathrm{~g} / \mathrm{kg}$; Sigma). The brains were transferred to a gradient of 10,20 , and $30 \%$ sucrose until they sank to the bottom of the container. Then, the brain samples were embedded in clear frozen sectioning compound (OCT, Sakura, USA) and cut into $30 \mu \mathrm{m}$ coronal sections with a cryostat microtome (CMS3050S, Leica Microsystems; Nussloch, Germany). IHC was performed essentially as described in our recent report [29]. The free-floating sections (3-4 sections per mouse) were incubated with primary antibodies (Table 1) overnight at room temperature. After three washes with PBS, the sections were incubated with the appropriate biotinylated secondary antibodies (1:200, Vector Laboratories; CA, USA) for $1 \mathrm{~h}$ at room temperature, followed by an incubation with an avidin-biotinperoxidase complex (ABC kit; Vector Laboratories) for $1 \mathrm{~h}$ at room temperature. The sections were washed with PBS (10 min, three times), and the signal was developed by a diaminobenzidine (DAB) kit (Vector Laboratories). After DAB staining, the slices were observed using a light microscope (Leica; Wetzlar, Germany). Images were obtained using Image-Pro Plus 5.1 software (Image-Pro Plus Media Cybernetics; Washington, MD, USA), and the threshold intensity was manually set according to a standard signal for all images. Pixel counts were derived from the average of three adjacent sections per animal.

\section{Western blot analyses}

Western blot analyses were completed as previously described [29]. Briefly, hippocampal samples were collected ( $n=5-8$ mice/group) and homogenized in RIPA lysis buffer (1:2, w/v). A bicinchoninic acid (BCA) protein assay kit (Pierce, Rockford, USA) was utilized to determine the protein concentration. Subsequently, $25 \mu \mathrm{g}$ of protein were loaded and separated on SDS-PAGE gels and transferred to a polyvinylidene fluoride (PVDF) membrane (Millipore). The membranes were blocked with TBS containing $0.05 \%$ Tween 20 (TBST) and 5\% skim milk for $1 \mathrm{~h}$ at $37^{\circ} \mathrm{C}$ and then incubated with primary antibodies (Table 1 ) for $16 \mathrm{~h}$ at $4{ }^{\circ} \mathrm{C}$. After washes 
Table 1 List of primary antibodies

\begin{tabular}{|c|c|c|c|c|c|}
\hline Antibody & Species & Supplier & IHC dilution & WB dilution & Catalogue no \\
\hline Iba-1 & Rabbit & Wako & $1: 1000$ & & $019-19,741$ \\
\hline GFAP & Mouse & Millipore & $1: 1000$ & & MAB360 \\
\hline NeuN & Mouse & Millipore & $1: 3000$ & & MAB377 \\
\hline ChAT & Rabbit & COVANCE & $1: 1000$ & & AB143 \\
\hline $5-\mathrm{HT}$ & Rat & Millipore & $1: 200$ & & MAB352 \\
\hline $\mathrm{TH}$ & Rabbit & Millipore & $1: 1000$ & & AB152 \\
\hline $6 \mathrm{E} 10$ & Mouse & Biolegend & & $1: 1000$ & SIG-39320 \\
\hline AßPP & Rabbit & Sigma-Aldrich & & $1: 1000$ & SAB3500274 \\
\hline Beta-secretase 1 (BACE1) & Rabbit & Cell Signaling & & $1: 1000$ & 5606 \\
\hline Insulin-degrading enzyme (IDE) & Mouse & Abcam & & $1: 1000$ & Ab32216 \\
\hline Neprilysin (NEP) & Mouse & Abcam & & $1: 1000$ & Ab81688 \\
\hline PSD95 & Rabbit & Abcam & & $1: 1000$ & Ab18258 \\
\hline synaptophysin & Rabbit & Abcam & & $1: 1000$ & Ab14692 \\
\hline GSK3 $\beta$ & Rabbit & Cell Signaling & & $1: 1000$ & $9315 S$ \\
\hline GSK3 $\beta$ (pS9) & Rabbit & Cell Signaling & & $1: 1000$ & 9336 \\
\hline Tau (pS202) & Rabbit & Anaspec & & $1: 1000$ & AS-28017 \\
\hline Tau (pT231) & Rabbit & Invitrogen & & $1: 1000$ & $44746 \mathrm{G}$ \\
\hline HT7 & Mouse & Thermo & & $1: 1000$ & MN1000 \\
\hline GAPDH & Mouse & Arigobio & & $1: 1000$ & ARG10112 \\
\hline
\end{tabular}

WB Western blot, IHC Immunohistochemistry

with TBST, the membranes were incubated with the secondary antibodies (1:10000, Amersham Pharmacia Biotech; Piscataway, NJ, USA) corresponding to the type of primary antibody for $1 \mathrm{~h}$ at room temperature. Glyceraldehyde-3-phosphate dehydrogenase (GAPDH) was used as a loading control. The membranes were developed using an enhanced chemiluminescence (ECL) detection reagent kit (Amersham Pharmacia Biotech) and visualized using an LAS-4000 chemiluminescence detection system (Fujifilm; Tokyo, Japan). Band densities were quantified using Gel-Pro Analyzer software (GelPro32, version 4.0; Media Cybernetics, Inc.; Rockville, MD, USA).

\section{Statistical analysis}

The data are presented as the means \pm standard errors of the means (SEM), and the statistical analysis was performed using one-way analysis of variance (ANOVA) followed by a post hoc least significant difference (LSD) test. Statistical and data analyses were carried out with IBM SPSS software 20.0 (SPSS; Chicago, IL, USA). A $P$ value of 0.05 or less was considered significant.

\section{Results}

PS128 supplementation prevented cognitive dysfunction in $3 \times \mathrm{Tg}$-AD mice administered icv-STZ

No differences identified in the blood glucose and anxiety levels were observed among all groups (Fig. S1B-E).
We measured short-term memory with the $\mathrm{Y}$ maze and spatial cognition with the MWM to further investigate the ability of the PS128 pretreatment to protect against the cognitive dysfunction induced by icv-STZ in mice. Based on the results of the $Y$ maze, the administration of PS128 or/and icv-STZ did not affect the total entry frequency, indicating that all groups of mice had the same ability to explore novel environments (Fig. 1A). Subsequently, the spontaneous alternation rate was decreased in the icv-STZ group compared to the icv-saline group of $3 \times \mathrm{Tg}$-AD mice $(P<0.05$, Fig. $1 \mathrm{~B})$. However, pretreatment with PS128 significantly prevented the decrease in the spontaneous alternation rate in $3 \times \mathrm{Tg}$ - $\mathrm{AD}$ mice treated with icv-STZ $(P<0.01$, Fig. 1B). The results indicate that the PS128 pretreatment prevented the shortterm memory deficit induced by icv-STZ in $3 \times \mathrm{Tg}-\mathrm{AD}$ mice. In addition to short-term memory, we further analyzed spatial learning and memory with the MWM test. First, we did not observe a significant difference in swimming ability among all groups of mice, suggesting that all groups of mice had the same level of motor activity (Fig. 1C). From the results of the learning curve, the time required to climb onto the hidden platform (escape latency) was decreased following training in $\mathrm{B} 6$ $(\mathrm{F}(3,30)=6.68, P<0.001$; Fig. $1 \mathrm{D})$ and $3 \times \mathrm{Tg}-\mathrm{AD}(\mathrm{F}(3$, $55)=4.45, P<0.01$; Fig. $1 \mathrm{D})$ mice in the saline/icv-saline group. However, the escape latency was not significantly reduced following training in $3 \times \mathrm{Tg}-\mathrm{AD}$ mice treated 


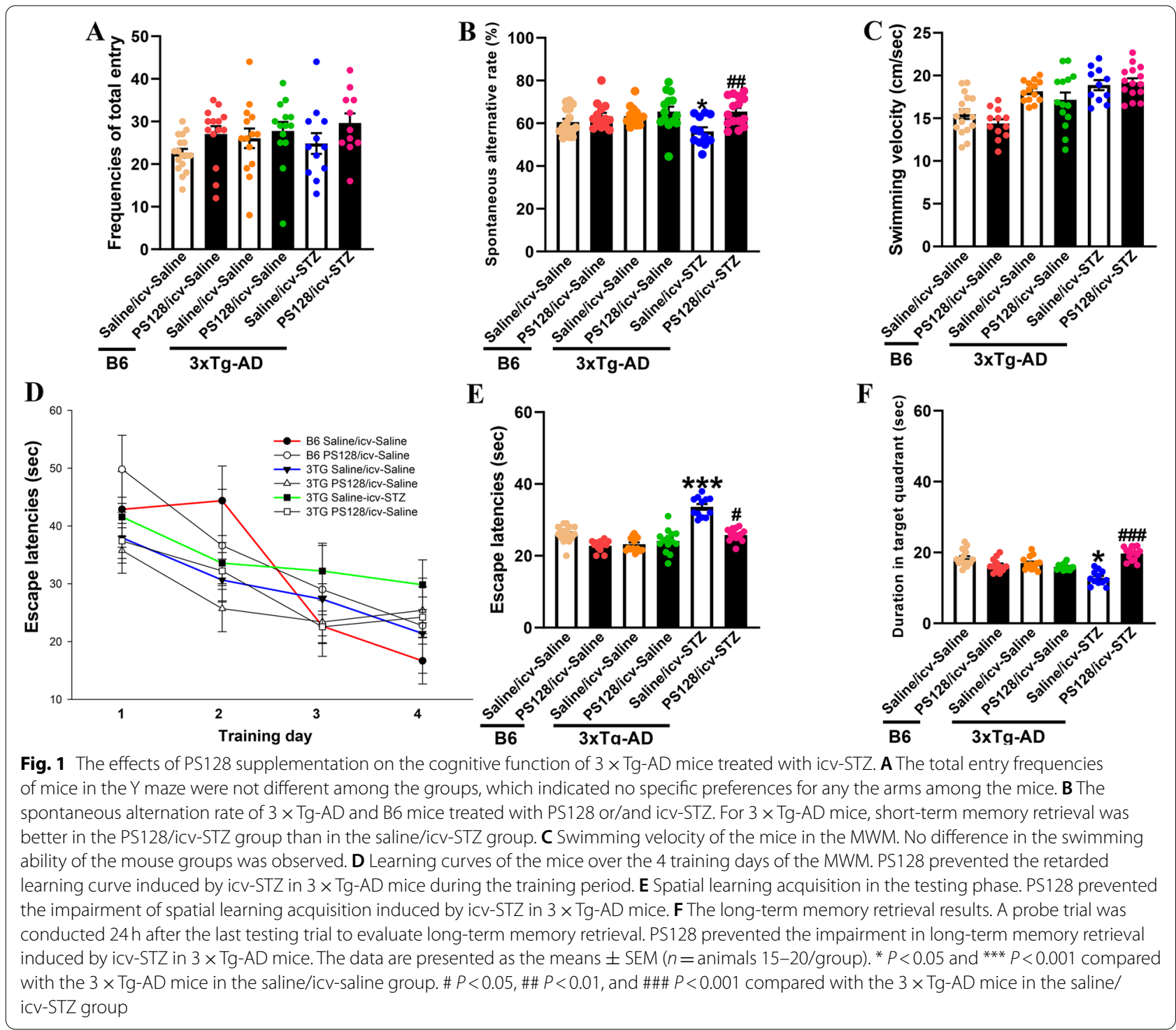

with saline/icv-STZ $(\mathrm{F}(3,39)=1.641, P>0.05$; Fig. 1D). The PS128 pretreatment prevented the impaired learning curve in $3 \times \mathrm{Tg}-\mathrm{AD}$ mice induced by icv-STZ (F(3) $59)=4.975, P<0.01$; Fig. 1D). For spatial learning acquisition (testing), the escape latencies were not significantly different between $\mathrm{B} 6$ and $3 \times \mathrm{Tg}$ - $\mathrm{AD}$ mice in the saline/ icv-saline group $(P>0.05$; Fig. $1 \mathrm{E})$. However, $3 \times \mathrm{Tg}-\mathrm{AD}$ mice in the saline/icv-STZ group required more time to reach the platform (escape latency) than mice in the saline/icv-saline group $(P<0.001$; Fig. $1 \mathrm{E})$, and PS128 significantly prevented the impairment in spatial learning acquisition induced by icv-STZ $(P<0.05$; Fig. $1 E)$. In the probe trials, the time spent in the target quadrant was not significantly different between $\mathrm{B} 6$ and $3 \times \mathrm{Tg}-\mathrm{AD}$ mice in the saline/icv-saline group $(P>0.05$; Fig. $1 \mathrm{~F})$. However, the length of time spent in the target quadrant was significantly decreased in $3 \times \mathrm{Tg}$ - $\mathrm{AD}$ mice in the saline/icvSTZ group compared with those in the saline/icv-saline group $(P<0.05$; Fig. 1 F). On the other hand, PS128 prevented the decrease in the length of time spent in the target quadrant by $3 \times \mathrm{Tg}$-AD mice treated with icv-STZ $(P<0.001$; Fig. 1F). Taken together, the PS128 pretreatment prevented the cognitive dysfunction induced by icv-STZ in $3 \times$ Tg-AD mice.

\section{PS128 supplementation prevented the increase in GSK3 $\beta$} activity and $A \beta$ production in $3 \times \mathrm{Tg}-\mathrm{AD}$ mice treated with icv-STZ

The early administration of icv-STZ induces cognitive dysfunction by increasing GSK3 $\beta$ activity and levels of 


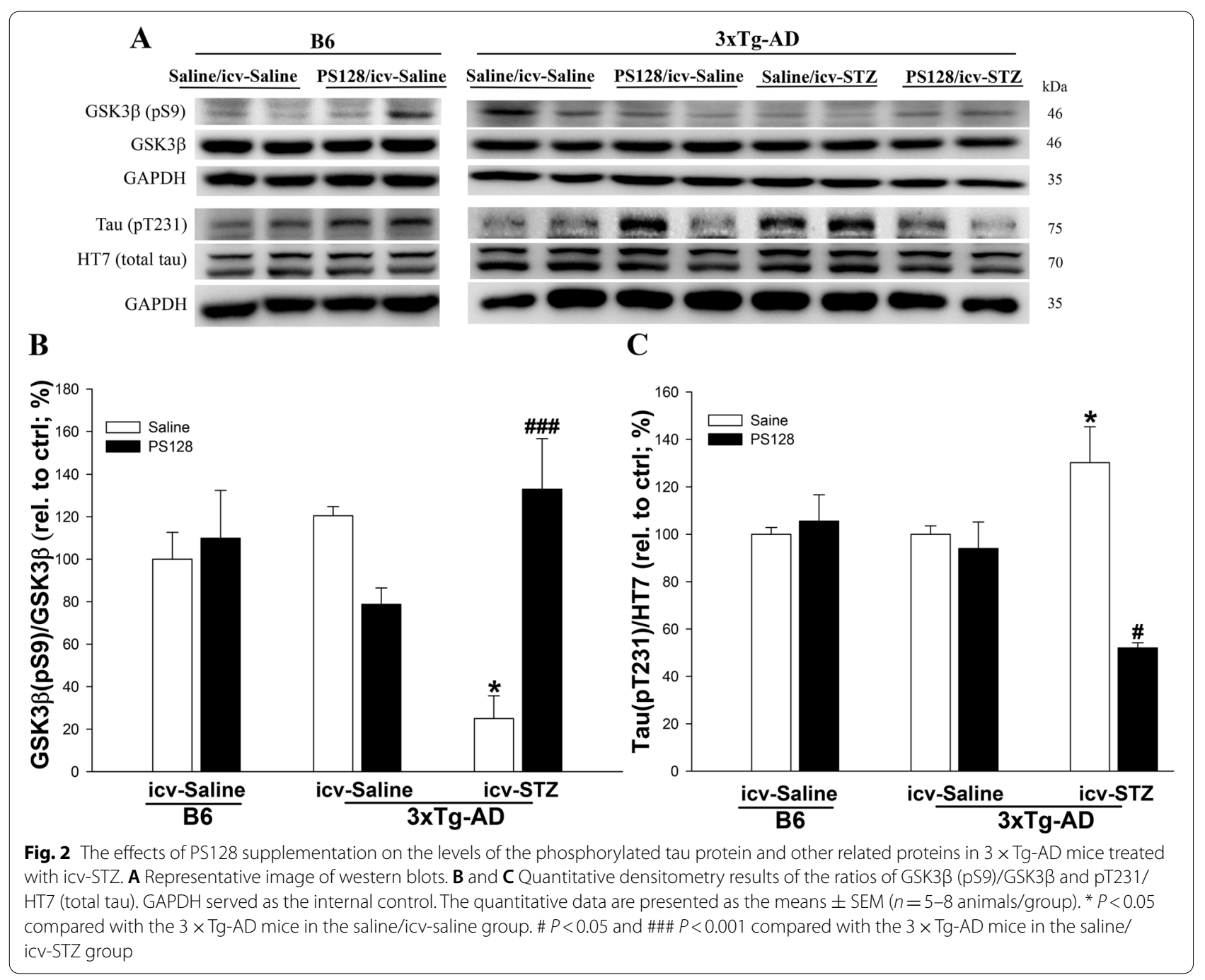

the phosphorylated tau protein [31]. Therefore, the levels of inactive GSk3 3 (pS9) and tau protein phosphorylation at T231 (pT231) and S202 (pS202) sites were measured in this study. In $3 \times \mathrm{Tg}$-AD mice, the levels of GSK3 $\beta$ (pS9) were significantly decreased in the saline/ icv-STZ group compared to the saline/icv-saline group $(P<0.05$; Fig. 2A-B $)$. However, the PS128 pretreatment significantly prevented the decrease in GSK3 $\beta$ (pS9) activation induced by icv-STZ in $3 \times \mathrm{Tg}$-AD mice $(P<0.01$; Fig. 2A-B). The levels of pT231, but not pS202, were significantly increased in $3 \times \mathrm{Tg}$-AD mice treated with saline/icv-STZ compared to saline/icv-saline mice $(P<0.05$; Fig. $2 \mathrm{~A}$ and $\mathrm{C}$ and Fig. S2A-B), and PS128 supplementation prevented the increase in levels the pT231 tau protein $(P<0.05$; Fig. $2 \mathrm{~A}$ and $C)$. In addition, the levels of GSK3 $\beta$ (pS9) and phosphorylated tau proteins were not significantly different between $\mathrm{B} 6$ and $3 \times \mathrm{Tg}-\mathrm{AD}$ mice treated with saline/icv-saline conditions $(P>0.05$; Fig. 2A-C and Fig. S2A-B). Except the changes in GSK3 $\beta$ activity and tau pT231 phosphorylation levels, the abnormal deposition of $A \beta$ produced by the sequential cleavage of $\beta$-site $A \beta P P$-cleaving enzyme (BACE1) and $\gamma$-secretase from A $\beta$ PP is a major pathological feature of $\mathrm{AD}$ [32]. Evidence has also suggested that an imbalance in $A \beta$ metabolic enzymes, including $B A C E 1$ for $A \beta$ production, insulin-degrading enzyme (IDE) and neprilysin (NEP) for A $\beta$ clearance, causes $A \beta$ deposition [33, 34]. Therefore, the levels of the $6 E 10$, BACE1, A $\beta P P$, IDE, and NEP proteins in the mouse hippocampus were examined using western blot analysis. Based on the immunoblot results, we did not observe significant differences in levels of the 6E10, BACE1, APP, IDE, and NEP proteins between $\mathrm{B} 6$ and $3 \times \mathrm{Tg}-\mathrm{AD}$ mice in the saline/icv-saline group $(P>0.05$; Fig. 3 and Fig. S2A, C and D). The levels of $6 \mathrm{E} 10(P<0.01$; Fig. 3A-B) and BACE1 $(P<0.05$; Fig. $3 \mathrm{~A}$ and $\mathrm{C})$ were significantly increased in $3 \times \mathrm{Tg}-\mathrm{AD}$ mice treated with saline/icv-STZ compared to mice treated with saline/ 


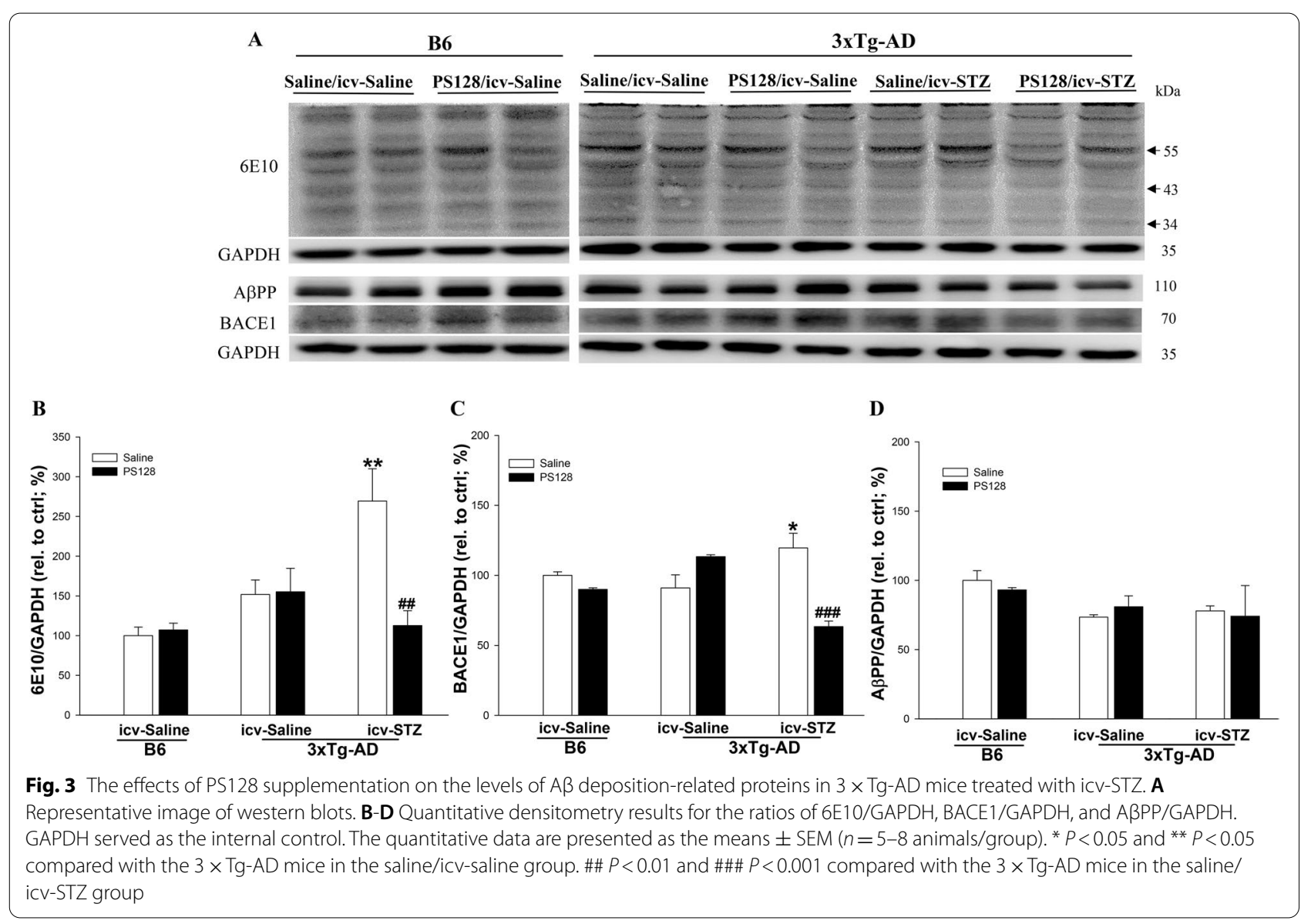

icv-saline. PS128 prevented the significant increase in 6E10 $(P<0.01$; Fig. 3A-B) and BACE1 $(P<0.001$; Fig. 3A and $C$ ) protein levels induced by icv-STZ in $3 \times$ Tg-AD mice. However, significant changes in the levels of APP, IDE, and NEP proteins were not observed in all mouse groups $(P>0.05$; Fig. $3 \mathrm{~A}$ and $\mathrm{D}$ and Fig. S2A, C, and D). These data suggest that PS128 prevented A $\beta$ deposition mediated by BACE1 and GSK3 $\beta$ (pS9) to protect against the toxicity induced by icv-STZ in $3 \times$ Tg-AD mice.

\section{PS128 supplementation reduced the fecal propionic acid} (PPA) levels in $3 \times$ Tg-AD mice treated with icv-STZ

The gas chromatography-mass spectrometry analysis of SCFAs revealed that the levels of PPA, acetic acid, and butyric acid were not different between $3 \times \mathrm{Tg}-\mathrm{AD}$ mice and B6 mice treated with saline/icvsaline (Fig. 4). The administration of icv-STZ significantly increased the fecal PPA levels in $3 \times$ Tg-AD mice $(P<0.05$; Fig. $4 A)$. In addition, PS128 supplementation prevented the increase in fecal PPA levels induced by icv-STZ in $3 \times$ Tg-AD mice $(P<0.01$; Fig. $4 \mathrm{~A})$. However, the administration of PS128 and/or icv-STZ did not alter the fecal acetic acid and butyric acid levels in $3 \times$ Tg-AD mice (Fig. 4B-C). Therefore, we suggest that PS128 supplementation prevented cognitive dysfunction in icv-STZ-treated $3 \times \mathrm{Tg}-\mathrm{AD}$ mice potentially through the modulation of PPA levels, but not acetic acid or butyric acid levels.

\section{PS128 supplementation prevented gliosis in $3 \times \mathrm{Tg}-\mathrm{AD}$ mice treated with icv-STZ}

The activation of astrocytes and microglia aggravates the neurodegenerative milieu through the release of proinflammatory mediators, which results in cognitive impairment [35, 36]. We performed staining with antibodies against glial fibrillary acidic protein (GFAP) and Iba1 to assess astrogliosis and microgliosis, respectively. The immunostaining results revealed significantly increased numbers of activated microglia, but not astrocytes, in $3 \times \mathrm{Tg}-\mathrm{AD}$ mice compared to $\mathrm{B} 6$ mice treated with saline/icv-saline 


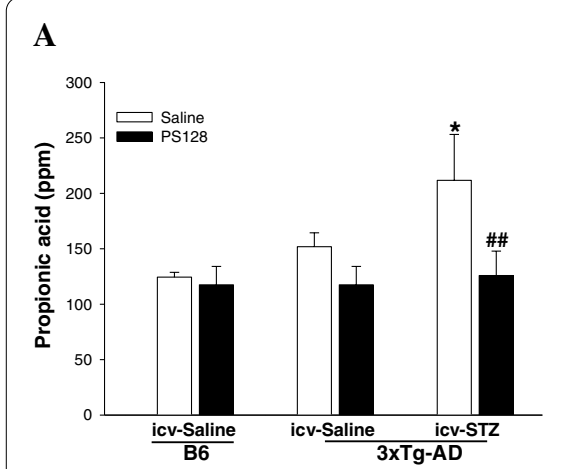

B

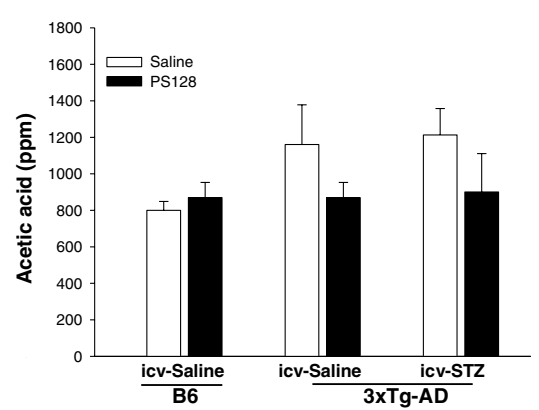

C

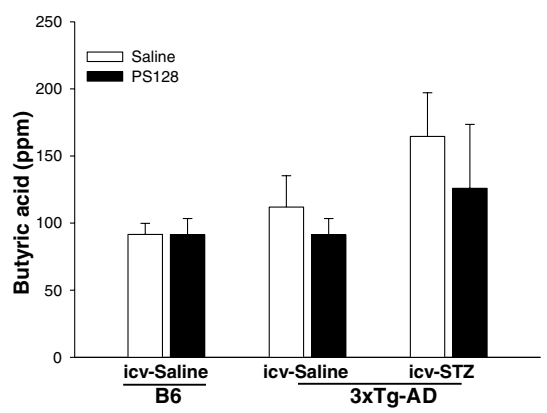

Fig. 4 The effects of PS128 supplementation on the fecal SCFA levels in $3 \times$ Tg-AD mice treated with icv-STZ. A The levels of PPA in fecal boli. The administration of icv-STZ increased the fecal PPA levels, while PS128 prevented this increase. B and C The levels of acetic acid and butyric acid in fecal boli. The administration of PS128 or/and icv-STZ had no effects on the levels of fecal acetic acid and butyric acid in mice. The quantitative data are presented as the means \pm SEM $\left(n=5\right.$ per group). ${ }^{*} P<0.05$ compared with the $3 \times$ Tg-AD mice in the saline/icv-saline group. \#\# $P<0.01$ compared with the $3 \times \mathrm{Tg}-\mathrm{AD}$ mice in the saline/icv-STZ group

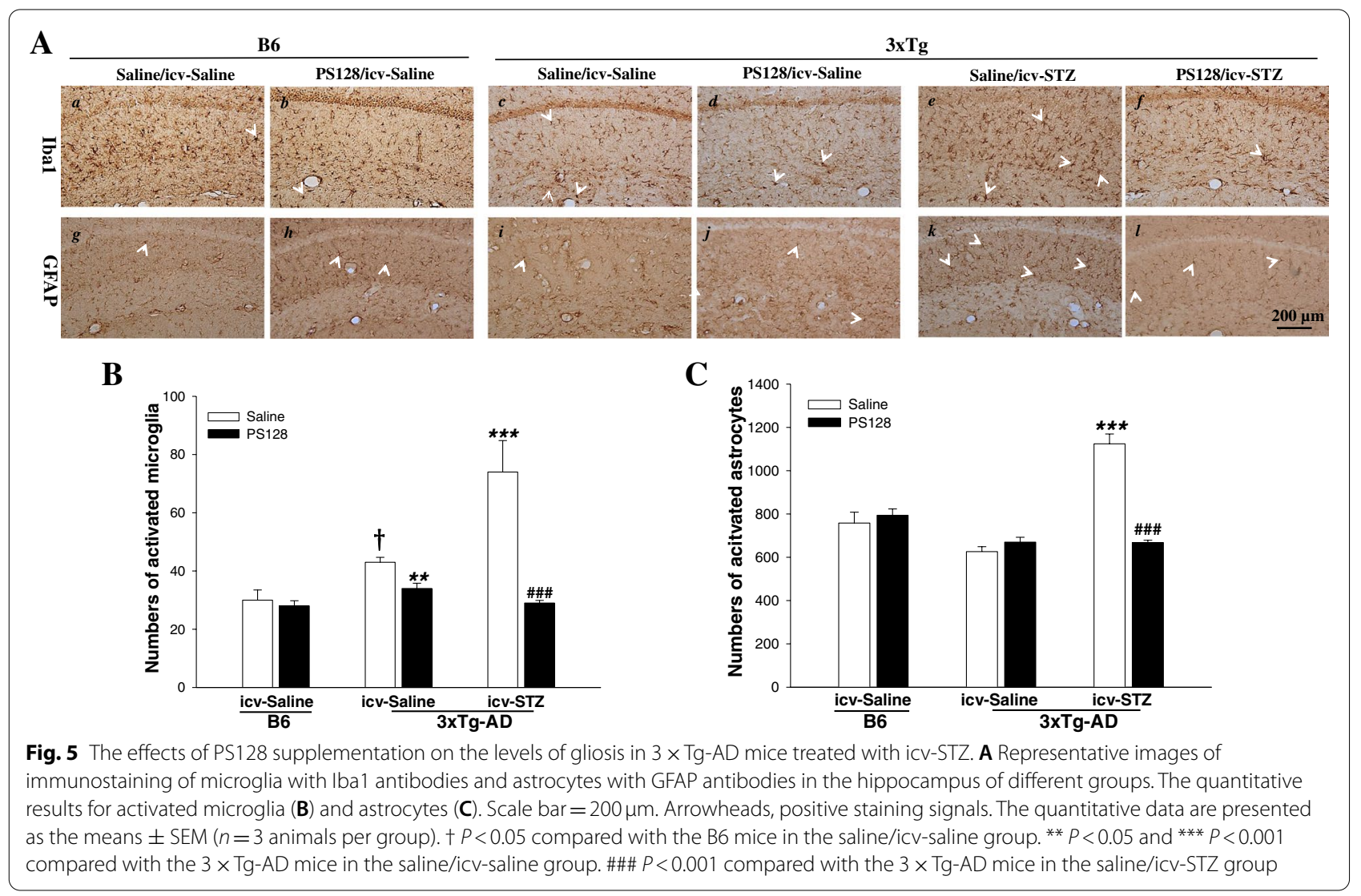

$(P<0.05$; Fig. $5 \mathrm{~A}-\mathrm{B})$. In $3 \times \mathrm{Tg}-\mathrm{AD}$ mice, the gliosis of astrocytes and microglia was significantly increased in the saline/icv-STZ group compared to the saline/ icv-saline group $(P<0.001$; Fig. 5A-C). However, PS128 prevented the gliosis induced by icv-STZ in $3 \times \mathrm{Tg}$-AD mice $(P<0.001$; Fig. $5 \mathrm{~A}-\mathrm{C})$. In addition, in $3 \times \mathrm{Tg}-\mathrm{AD}$ mice, microgliosis was significantly decreased in the PS128/icv-saline group compared to the saline/icv-saline group $(P<0.01$; Fig. $5 \mathrm{~A}-\mathrm{B})$. Based on these data, PS128 prevented icv-STZ-induced gliosis in $3 \times \mathrm{Tg}-\mathrm{AD}$ mice. 


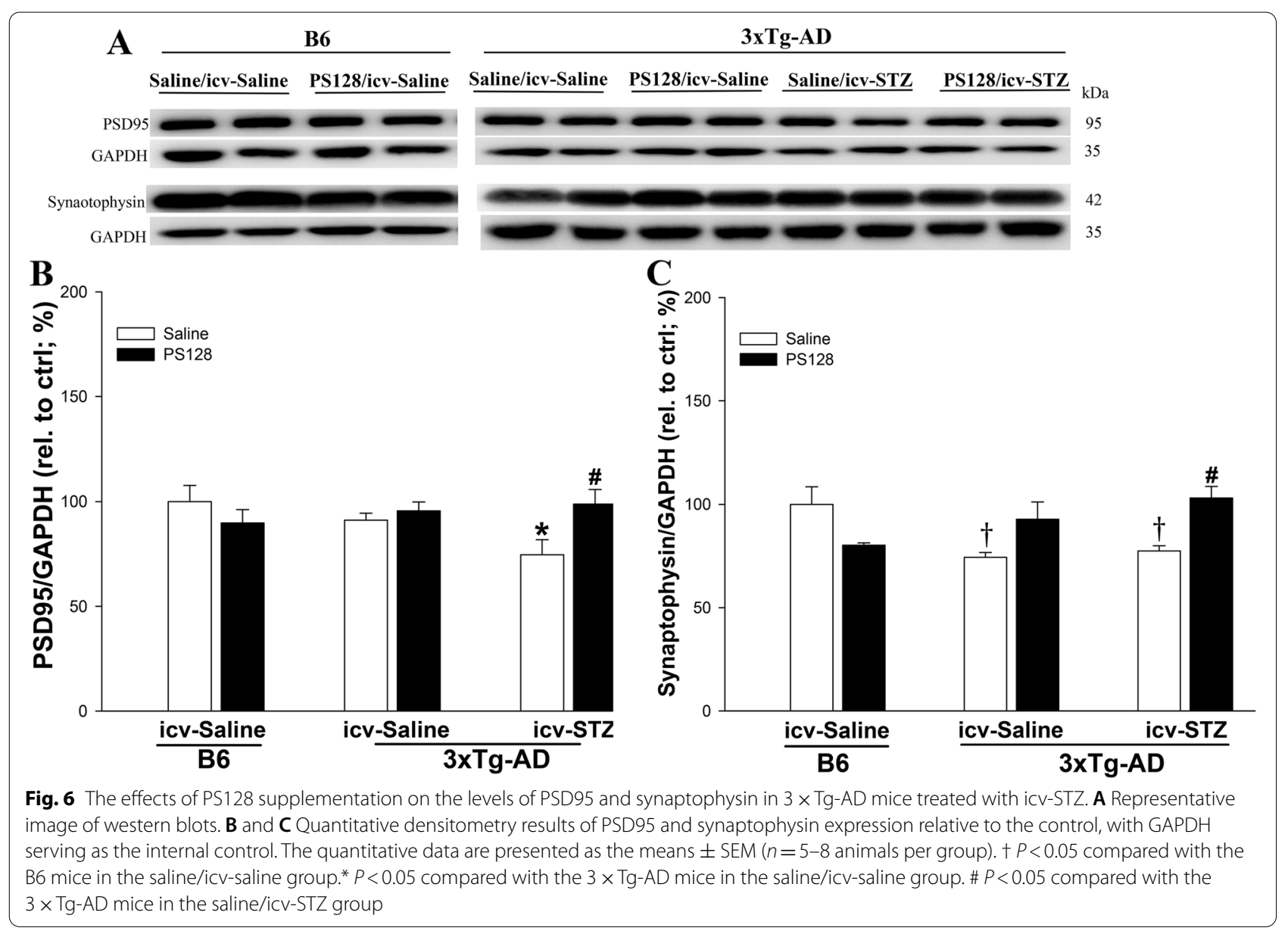

PS128 supplementation prevented the decrease in PSD95 and synaptophysin expression levels in the $3 \times \mathrm{Tg}-\mathrm{AD}$ mice treated with icv-STZ

Synaptic proteins, including postsynaptic density protein 95 (PSD95) and synaptophysin, play critical roles in synaptic plasticity and cognitive function $[37,38]$. Therefore, the levels of PSD95 and synaptophysin proteins were examined using western blot analyses. The level of synaptophysin, but not that of PSD95, was significantly reduced in $3 \times \mathrm{Tg}$ - $\mathrm{AD}$ mice compared to $\mathrm{B} 6$ mice treated with saline/icv-saline $(P<0.05 ;$ Fig. 6$)$. In $3 \times$ Tg-AD mice, the PSD95 expression level was significantly decreased after treatment with saline/icv-STZ compared to animals treated with saline/icv-saline $(P<0.05$; Fig. 6A-B). However, PS128 supplementation prevented the decrease in PSD95 $(P<0.05$; Fig. 6A-B) and synaptophysin $(P<0.01$; Fig. $6 \mathrm{~A}$ and $C)$ expression levels caused by icv-STZ in $3 \times$ Tg-AD mice. Thus, PS128 supplementation in $3 \times \mathrm{Tg}$-AD mice prevented the decreases in the levels of the synaptic proteins PSD95 and synaptophysin induced by icv-STZ.
PS128 supplementation prevented the loss of neurons related to cognitive function in $3 \times \mathrm{Tg}-\mathrm{AD}$ mice treated with icv-STZ

The number of neurons related to cognition was evaluated in this study to determine whether PS128 or/and icv-STZ affected pyramidal neurons in the CA1 region of the hippocampus, cholinergic neurons in the medial septum/diagnoid band (MS/DB), serotonergic neurons in the raphe nucleus, and noradrenergic neurons in the locus coeruleus (LC). Based on the immunostaining results (Fig. 7 and Table 2), only the number of cholinergic neurons was significantly decreased in $3 \times \mathrm{Tg}-\mathrm{AD}$ mice compared to B6 mice treated with saline/icvsaline $(P<0.001)$. In addition, in $3 \times \mathrm{Tg}-\mathrm{AD}$ mice, the loss of pyramidal neurons $(P<0.01)$, cholinergic neurons $(P<0.001)$, serotonergic neurons $(P<0.001)$, and noradrenergic neurons $(P<0.01)$ was significantly increased in the saline/icv-STZ group compared to the saline/icv-saline group. However, PS128 supplementation prevented the loss of pyramidal neurons $(P<0.01)$, cholinergic neurons $(P<0.05)$, serotonergic neurons 


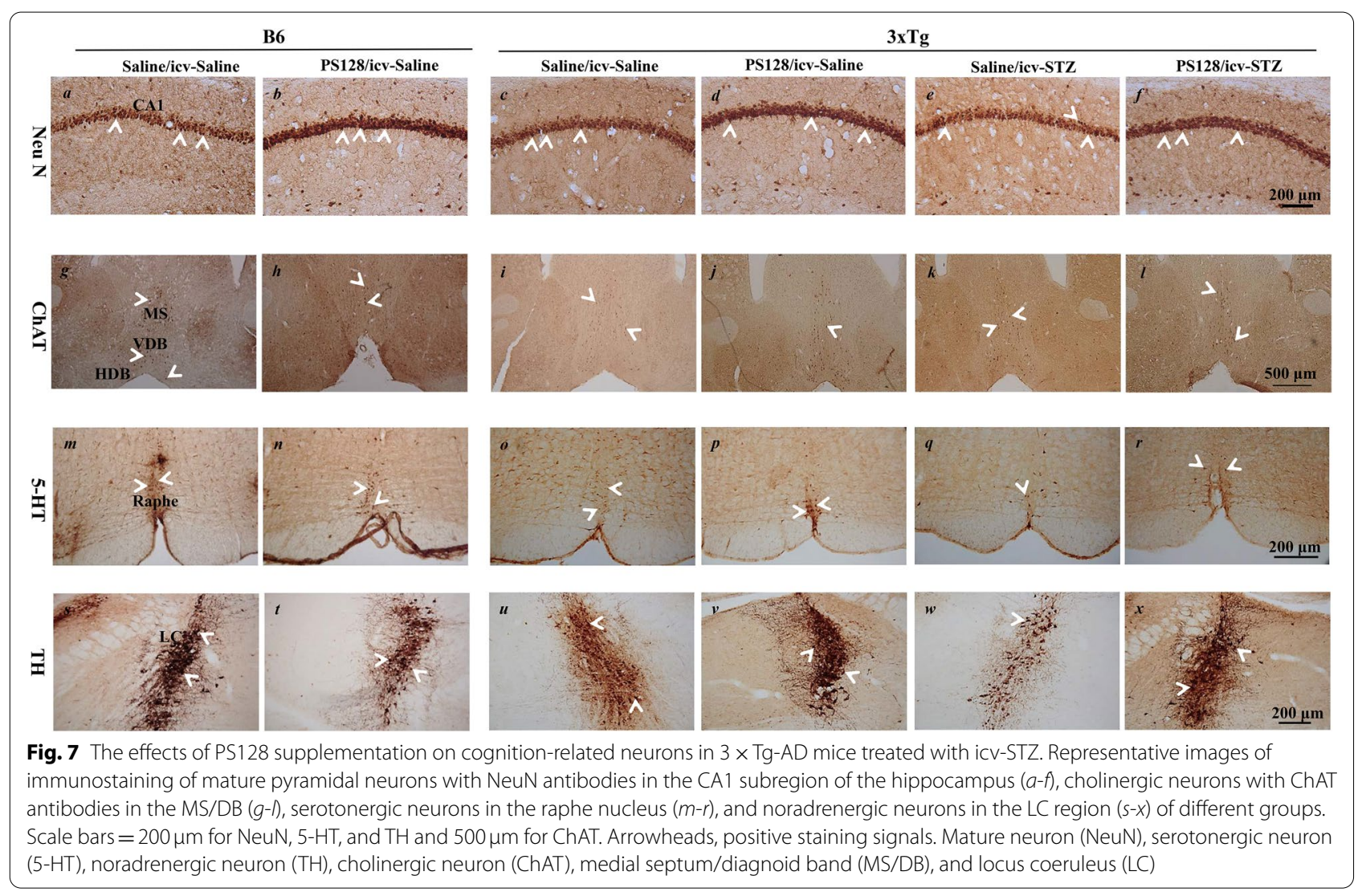

Table 2 Quantification of the numbers of cognition-related neurons in mice

\begin{tabular}{|c|c|c|c|c|c|c|}
\hline & \multirow{2}{*}{\multicolumn{2}{|c|}{$\frac{\text { B6 }}{\text { icv-saline }}$}} & \multicolumn{4}{|l|}{$3 x T g-A D$} \\
\hline & & & \multicolumn{2}{|l|}{ icv-saline } & \multicolumn{2}{|l|}{ icv-STZ } \\
\hline & Saline & PS128 & Saline & PS128 & Saline & PS128 \\
\hline NeuN & $1299.8 \pm 119.4$ & $1576.6 \pm 98.1$ & $1356.5 \pm 157.2$ & $1266.3 \pm 81.3$ & $784.3 \pm 109.7^{* *}$ & $1305.2 \pm 64.0^{\# \#}$ \\
\hline ChAT & $830.3 \pm 68.7$ & $944.7 \pm 24.1$ & $547.5 \pm 13.3^{t+t}$ & $491.0 \pm 15.3$ & $234.0 \pm 36.5^{* * *}$ & $390.7 \pm 60.4^{\#}$ \\
\hline 5-HT & $136.0 \pm 17.2$ & $107.5 \pm 7.8$ & $63.3 \pm 29.2$ & $125.3 \pm 7.1$ & $46.0 \pm 1.6^{* * *}$ & $118.3 \pm 27.8^{\# \#}$ \\
\hline TH & $324.9 \pm 22.3$ & $271.0 \pm 31.8$ & $289.8 \pm 33.2$ & $266.5 \pm 22.5$ & $162.8 \pm 9.2^{* *}$ & $296.7 \pm 25.5^{\# \# \#}$ \\
\hline
\end{tabular}

${ }^{\dagger}$ Compared to $\mathrm{B} 6$ mice in the icv-saline/saline group

* Compared to 3xTg-AD mice in the icv-saline/saline group

\# Compared to 3xTg-AD mice in the icv-STZ/saline group

${ }^{+1+} P<0.001$

${ }^{* *} P<0.01 ;{ }^{* * *} P<0.001$

${ }^{\#} P<0.05 ;{ }^{\# \#} P<0.01 ; \# \#<0.001$

$(P<0.01)$, and noradrenergic neurons $(P<0.001)$, protecting against the damage induced by icv-STZ in $3 \times$ Tg-AD mice. These results show that PS128 supplementation prevented the loss of neurons related to cognitive function in $3 \times \mathrm{Tg}$ - $\mathrm{AD}$ mice treated with icv-STZ.

\section{Discussion}

According to our findings, the administration of icv-STZ exacerbated the disease progression of $\mathrm{AD}$ via gliosis that resulted from an increases in the levels of fecal PPA and the inactive form of GSK3 $\beta$ in $3 \times \mathrm{Tg}$-AD mice. However, PS128 supplementation prevented the deleterious effects of icv-STZ on $3 \times \mathrm{Tg}$-AD mice. In addition, we did not 
observe a difference in cognitive function between B6 wild-type and $3 \times \mathrm{Tg}$-AD mice, as only a few changes in microgliosis, synaptophysin protein expression levels, and cholinergic neurons were observed at 7 months of age. Furthermore, PS128 supplementation alone did not exert significant toxic effects on B6 wild-type mice and only decreased the level of the number of activated microglia in the hippocampus of naïve $3 \times \mathrm{Tg}$ - $\mathrm{AD}$ mice. Gliosis resulting from PPA and GSK $3 \beta$ was considered one of the possible mechanisms that attenuated disease progression in the AD mouse model. Therefore, PS128 supplementation is a safe and potential preventive strategy for AD progression.

In $3 \times \mathrm{Tg}$-AD mice, the administration of icv-STZ induced cognitive dysfunction resulting from gliosis by increasing the levels of GSK3 $\beta$ activity and PPA. In addition, gliosis was associated with increased $\mathrm{A} \beta$ deposition, phosphorylation of tau at site T231 (pT231), and BACE1 levels and decreased levels of the postsynaptic protein PSD95 and numbers of cognition-related neurons, including pyramidal neurons in the CA1 subregion of the hippocampus, cholinergic neurons in the MS/DB, serotonergic neurons in the raphe nucleus, and noradrenergic neurons in the LC. These findings of the progression of cognitive dysfunction induced by icv-STZ in $3 \times \mathrm{Tg}-\mathrm{AD}$ mice are consistent with many other studies [27, 39, 40]. In addition, the administration of icv-STZ triggers insulin resistance and then impairs insulin signaling in the brain [41], but the peripheral glucose level was not changed in $3 \times \mathrm{Tg}-\mathrm{AD}$ mice, as shown in previous study [23]. Insulin resistance is associated with the modulation of amyloid production, tau phosphorylation and neuroinflammation through the regulation of GSK3 $\beta$ activity $[42,43]$. Furthermore, GSK3 $\beta$ activation subsequently leads to a number of changes, among which tau hyperphosphorylation [44] and increased $A \beta$ production by activated BACE1 [45] play a significant role in AD pathogenesis. The phosphorylation of tau at site T231 precedes phosphorylation at the S202 site in individuals with AD $[46,47]$, and pT231 was the primary site phosphorylated by GSK3 $\beta$ [48]. In addition, the administration of icv-STZ to $3 \times \mathrm{Tg}-\mathrm{AD}$ mice increased the expression levels of BACE1, but not A $\beta$ PP, IDE or NEP. Many studies have also suggested that icv-STZ increases GSK3 $\beta$ activity and subsequently regulates $A \beta$ deposition by modulating BACE1 expression [27, 31, 49, 50]. The substantially increased deposition of $A \beta$ might be mediated by the regulation of both BACE1 and GSK3 $\beta$ activity in the $3 \times \mathrm{Tg}$-AD mice treated with icv-STZ. The deposition of $A \beta$ and phosphorylated tau protein triggers a series of reactions, including gliosis and synaptic dysfunction, resulting in neurodegeneration [51-53]. Accumulating evidence has also indicated that excess PPA crosses the blood-brain barrier and then induces gliosis $[54,55]$. A reduction in the neuron number and increase in gliosis were identified in the PPA-treated brain [56]. Excess PPA exerts many negative effects, including gliosis and ASDs [55, 57-59]. The association described above indicates that increased GSK3 $\beta$ activity and fecal PPA levels might increase gliosis. A previous meta-analysis also reported the loss of cholinergic neurons in the nucleus basalis, serotonergic neurons in the raphe nucleus, and noradrenergic neurons in the $\mathrm{LC}$ of patients with $\mathrm{AD}[60,61]$. Based on the combination of the genetic $(3 \times \mathrm{Tg}-\mathrm{AD}$ mice $)$ and environmental (the type $3 \mathrm{AD}$ ) factors, and the phenotypic features described above, icv-STZ administration to $3 \times \mathrm{Tg}$-AD mice was proven to be a reliable animal model to evaluate the effects and mechanisms of PS128 in AD mice.

Results from a recent randomized, double-blind, placebo-controlled trial of younger (aged 7-15) individuals with autism spectrum disorder (ASD) in Taiwan showed that PS128 ameliorates opposition/defiance behaviors [62]. PS128 also exerts anxiolytic effects on stressed mice $[16,17]$. In addition, PS128 is safe for human consumption, according to toxicological assessments [63]. In this study, we assessed the effect of PS128 on the icvSTZ-treated $3 \times \mathrm{Tg}$-AD model and showed that longterm supplementation with PS128 prevented cognitive dysfunction induced by icv-STZ in the $3 \times \mathrm{Tg}-\mathrm{AD}$ male mice. The beneficial effects of PS128 supplementation on attenuating cognitive deficits were consistent with many other probiotic studies [14, 64-67]. Therefore, we suggest that PS128 supplementation is safe and has the potential to prevent cognitive dysfunction in individuals with $\mathrm{AD}$.

PS128 supplementation alters hyperactive and emotional behaviors by modulating the levels of monoamine neurotransmitters and systemic inflammation $[16,17$, 68]. Researchers have not clearly determined whether changes in metabolites such as SCFAs, the main metabolites of gut microbiota, are modulated by the beneficial effect of PS128 on AD. SCFAs are often considered critical candidate mediators of gut-brain communication, and altered SCFA production has been reported in a variety of neuropathologies [69]. In the current study, PS128 supplementation prevented the increase in fecal PPA levels induced by icv-STZ in $3 \times \mathrm{Tg}$-AD mice. The results seem inconsistent with some previous evidence suggesting that SCFAs, including acetic acid, butyric acid, and PPA, exerted positive effects on individuals with $\mathrm{AD}[70,71]$. However, the results of a recent bioinformatics analysis indicated that PPA specifically plays an important role in $\mathrm{AD}$ pathogenesis [54]. PPA levels also play an important role in insulin resistance [72] and are increased in subjects with type 2 diabetes mellitus [73] due to alterations in the environment of the gut microbiota $[74,75]$. PPA 


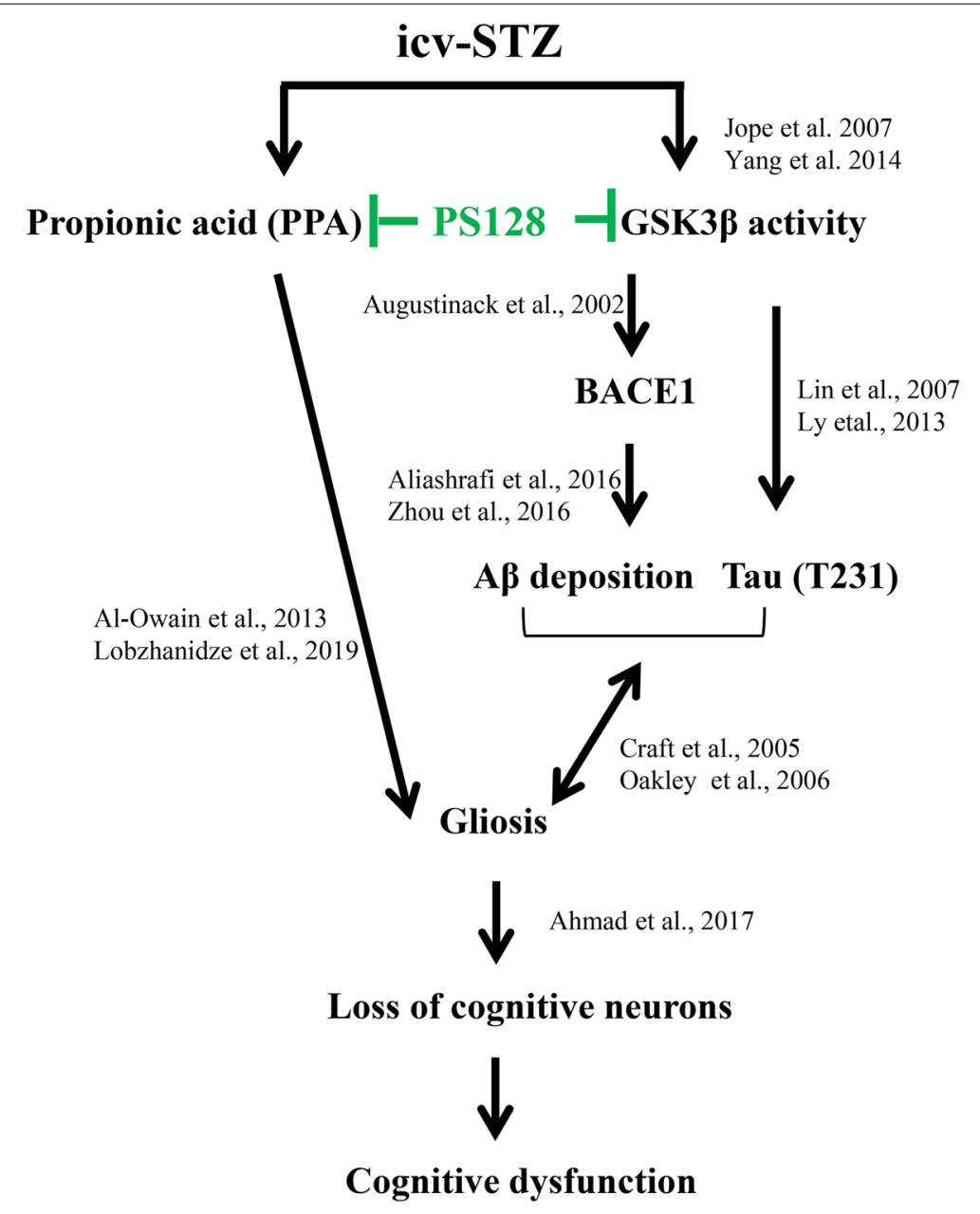

Fig. 8 The proposed effect of PS128 supplementation on $3 \times$ Tg-AD mice treated with icv-STZ. The icv-STZ treatment substantially increased gliosis by increasing GSK3 $\beta$ activity and fecal PPA levels, resulting in cognitive dysfunction in $3 \times$ Tg-AD mice. However, PS128 supplementation prevented the damage induced by icv-STZ, possibly by reducing PPA levels, GSK3 $\beta$ activity, and gliosis in $3 \times \mathrm{Tg}$-AD mice, which further ameliorated the behavioral and pathological features of AD

readily crosses the gut-blood barrier and then enters the central nervous system to impair spatial cognitive behavior [76-78]. Furthermore, probiotics restore the normal gut microbiota and protect against damage induced by PPA [79]. Probiotics significantly improve the cognitive function of $3 \times \mathrm{Tg}$-AD mice by increasing neuronal activity, attenuating gliosis, mitigating synaptic deficits, and reducing the levels of phosphorylated tau though the inhibition of GSK3 $\beta$ activity [80]. Therefore, the modulation of the levels of PPA and GSK3 $\beta$ activity by PS128 supplementation may play a role in preventing cognitive dysfunction and promoting memory consolidation in the $3 \times \mathrm{Tg}-\mathrm{AD}$ mice treated with icv-STZ, as shown in Fig. 8 . However, further studies are needed to elucidate whether the other mechanisms mediating the beneficial effects of PS128 on cognition are involved.

\section{Conclusions}

In summary, the administration of icv-STZ substantially increased levels of gliosis resulting from increased GSK $3 \beta$ activity and fecal PPA levels in $3 \times$ Tg-AD mice. PS128 supplementation prevented the damage induced by icv-STZ by reducing the levels of fecal PPA, GSK3 $\beta$ activity, and gliosis in $3 \times \mathrm{Tg}$ - $\mathrm{AD}$ mice. Therefore, the PS128 supplementation represents a potential strategy to prevent and/or delay the progression of AD.

\section{Abbreviations}

PS128: Lactobacillus plantarum PS128; AD: Alzheimer's disease; CFU: Colonyforming unit; icv: Intracerebroventricular; STZ: Streptozotocin; o.g.: Oral gavage; $A \beta$ : Amyloid- $\beta$; NFTs: Neurofibrillary tangles; A $\beta P P$ : Amyloid- $\beta$ protein precursor; BACE1: $\beta$-site ABPP-cleaving enzyme; GSK3 $\beta$ : Glycogen synthase kinase 3 beta; SCFAs: Short-chain fatty acids; PPA: Propionic acid levels; PSD95: Postsynaptic density protein 95; MS/DB: Medial septum/diagnoid band; ChAT: Choline acetyltransferase; OFT: Open field test; EPM: Elevated plus maze; 
MWM: Morris water maze; IHC: Immunohistochemistry; DAB: Diaminobenzidine; GFAP: Glial fibrillary acidic protein; Iba1: Ionized calcium binding adaptor molecule 1; LC: Locus coeruleus; TH: Thyroxine hydroxylase; 5-HT: 5-hydroxytryptamine; PVDF: Polyvinylidene fluoride; GAPDH: Glyceraldehyde-3-phosphate dehydrogenase; IDE: Insulin-degrading enzyme; NEP : Neprilysin.

\section{Supplementary Information}

The online version contains supplementary material available at https://doi. org/10.1186/s12906-021-03426-8.

Additional file 1: Figure S1. The effects of PS128 supplementation on anxiety behavior in $3 \times \mathrm{Tg}-\mathrm{AD}$ mice treated with icv-STZ. Figure $\mathbf{S 2}$. The effects of PS128 supplementation on the levels of tau (pS202), IDE, and NEP protein expression in $3 \times \mathrm{Tg}-\mathrm{AD}$ mice treated with icv-STZ.

Figure S3. Original Uncropped Western blots for GSK3 $\beta$ related protein.

Figure S4. Original Uncropped Western blots for phosphorylated Tau protein. Figure S5. Original Uncropped Western blots for 6E10 protein. Figure S6. Original Uncropped Western blots for BACE1 protein. Figure S7. Original Uncropped Western blots for ABPP protein. Figure S8. Original Uncropped Western blots for PSD95 protein. Figure S9. Original Uncropped Western blots for synaptophysin protein.

\section{Acknowledgments}

We thank Min-Yu Chang, Yun-Fang Cheng, and Chin-Lin Huang for their assistance in collecting samples from the mice. We also appreciate the assistance provided by the Molecular Imaging Core Facility of National Taiwan Normal University under the auspices of the Ministry of Science and Technology. PS128 was provided by Bened Biomedical Co., Ltd., Taipei, Taiwan.

\section{Authors' contributions}

$\mathrm{HJH}$ designed the experiments, wrote the manuscript, and executed the statistical analysis. JLC, YHC, MWC, YYK, and JFL conducted the experiments. $\mathrm{CCH}$ provided the experimental materials. YCT designed the experiments and reviewed the manuscript. HMHL designed the experiments, wrote the manuscript, and organized the final version of the manuscript. All authors have reviewed and approved this final manuscript.

\section{Funding}

Financial assistance was provided by grants from the Ministry of Science and Technology (MOST; 107-2320-B-003-007 and 108-2320-B-003-002) and MacKay Junior College of Medicine, Nursing and Management (MKC107R01 and MKC1070412). The funding bodies had no role in designing the study, the collection, analysis, and interpretation of data, or in writing the manuscript.

\section{Availability of data and materials}

The dataset used and/or analyzed during the current study are available from the corresponding author upon reasonable request.

\section{Declarations}

\section{Ethics approval and consent to participate}

The animals were maintained and treated in accordance with the principles of the Institutional Animal Care and Use Committee (IACUC) of National Taiwan Normal University, Taipei, Taiwan (Permit Number: 106036).

\section{Consent for publication}

Not applicable.

\section{Competing interests}

The authors have no competing interests to declare.

\section{Author details}

${ }^{1}$ Department of Nursing, MacKay Junior College of Medicine, Nursing and Management, Taipei 11260, Taiwan. ${ }^{2}$ Department of Life Science, National Taiwan Normal University, Taipei 11677, Taiwan. ${ }^{3}$ Institute of Biochemistry and Molecular Biology, National Yang Ming Chiao Tung University, Taipei 11221, Taiwan. ${ }^{4}$ Bened Biomedical Co., Ltd., Taipei 10448, Taiwan.
Received: 5 January 2021 Accepted: 27 September 2021

Published: 9 October 2021

\section{References}

1. Au A, Feher A, Mcphee L, Jessa A, Oh S, Einstein G. Estrogens, inflammation and cognition. Front Neuroendocrinol. 2016;40:87-100. https://doi. org/10.1016/j.yfrne.2016.01.002.

2. Lane CA, Hardy J, Schott JM. Alzheimer's disease. Eur J Neurol. 2018;25(1):59-70. https://doi.org/10.1111/ene.13439.

3. Nebel RA, Aggarwal NT, Barnes LL, Gallagher A, Goldstein JM, Kantarci K, et al. Understanding the impact of sex and gender in Alzheimer's disease: a call to action. Alzheimers Dement. 2018;14(9):1171-83. https://doi.org/ 10.1016/j.jalz.2018.04.008.

4. Scheltens P, Blennow K, Breteler MM, De Strooper B, Frisoni GB, Salloway S, et al. Alzheimer's disease. Lancet. 2016:388(10043):505-17. https://doi. org/10.1016/S0140-6736(15)01124-1.

5. Cummings JL, MorstorfT, Zhong K. Alzheimer's disease drug-development pipeline: few candidates, frequent failures. Alzheimers Res Ther. 2014;6(4):37. https://doi.org/10.1186/alzrt269.

6. Bostanciklioglu M. The role of gut microbiota in pathogenesis of Alzheimer's disease. J Appl Microbiol. 2019;127(4):954-67. https://doi.org/10. 1111/jam.14264.

7. Cryan JF, O'riordan KJ, Cowan CSM, Sandhu KV, Bastiaanssen TFS, Boehme M, et al. The microbiota-gut-brain axis. Physiol Rev. 2019;99(4):1877-2013. https://doi.org/10.1152/physrev.00018.2018.

8. Li B, He Y, Ma J, Huang P, Du J, Cao L, et al. Mild cognitive impairment has similar alterations as Alzheimer's disease in gut microbiota. Alzheimers Dement. 2019;15(10):1357-66. https://doi.org/10.1016/j.jalz.2019.07.002.

9. Zilberter Y, Zilberter M. The vicious circle of hypometabolism in neurodegenerative diseases: ways and mechanisms of metabolic correction. J Neurosci Res. 2017;95(11):2217-35. https://doi.org/10.1002/jnr.24064.

10. Caracciolo B, Xu W, Collins S, Fratiglioni L. Cognitive decline, dietary factors and gut-brain interactions. Mech Ageing Dev. 2014;136-137:59-69. https://doi.org/10.1016/j.mad.2013.11.011.

11. Erny D, Hrabe De Angelis AL, Jaitin D, Wieghofer P, Staszewski O, David E, et al. Host microbiota constantly control maturation and function of microglia in the CNS. Nat Neurosci. 2015;18(7):965-77. https://doi.org/10. 1038/nn.4030.

12. Akbari E, Asemi Z, Daneshvar Kakhaki R, Bahmani F, Kouchaki E, Tamtaji $\mathrm{OR}$, et al. Effect of probiotic supplementation on cognitive function and metabolic status in Alzheimer's disease: a randomized, double-blind and controlled trial. Front Aging Neurosci. 2016;8:256. https://doi.org/10. 3389/fnagi.2016.00256

13. O'hagan C, Li JV, Marchesi JR, Plummer S, Garaiova I, Good MA. Long-term multi-species Lactobacillus and Bifidobacterium dietary supplement enhances memory and changes regional brain metabolites in middleaged rats. Neurobiol Learn Mem. 2017;144:36-47. https://doi.org/10. 1016/j.nlm.2017.05.015.

14. Nimgampalle M, Kuna Y. Anti-alzheimer properties of probiotic, Lactobacillus plantarum MTCC 1325 in Alzheimer's disease induced albino rats. J Clin Diagn Res. 2017;11(8):KC01-5. https://doi.org/10.7860/JCDR/2017/ 26106.10428

15. Woo JY, Gu W, Kim KA, Jang SE, Han MJ, Kim DH. Lactobacillus pentosus var. plantarum C29 ameliorates memory impairment and inflammaging in a D-galactose-induced accelerated aging mouse model. Anaerobe. 2014;27:22-6. https://doi.org/10.1016/j.anaerobe.2014.03.003.

16. Liu WH, Chuang HL, Huang YT, Wu CC, Chou GT, Wang S, et al. Alteration of behavior and monoamine levels attributable to Lactobacillus plantarum PS128 in germ-free mice. Behav Brain Res. 2016;298(Pt B):202-9. https://doi.org/10.1016/j.bbr.2015.10.046.

17. Liu YW, Liu WH, Wu CC, Juan YC, Wu YC, Tsai HP, et al. Psychotropic effects of Lactobacillus plantarum PS128 in early life-stressed and naive adult mice. Brain Res. 2016;1631:1-12. https://doi.org/10.1016/j.brainres.2015. 11.018

18. Liao JF, Cheng YF, Li SW, Lee WT, Hsu CC, Wu CC, et al. Lactobacillus plantarum PS128 ameliorates 2,5-Dimethoxy-4-iodoamphetamine-induced tic-like behaviors via its influences on the microbiota-gut-brain-axis. Brain Res Bull. 2019;153:59-73. https://doi.org/10.1016/j.brainresbull.2019.07. 027. 
19. Bekkering P, Jafri I, Van Overveld FJ, Rijkers GT. The intricate association between gut microbiota and development of type 1, type 2 and type 3 diabetes. Expert Rev Clin Immunol. 2013;9(11):1031-41. https://doi.org/ 10.1586/1744666X.2013.848793

20. Steen E, Terry BM, Rivera EJ, Cannon JL, Neely TR, Avares R, et al. Impaired insulin and insulin-like growth factor expression and signaling mechanisms in Alzheimer's disease--is this type 3 diabetes? J Alzheimers Dis. 2005;7(1):63-80. https://doi.org/10.3349/ymj.2017.58.3.479.

21. Mosconi L, Sorbi S, De Leon MJ, NB LY, Myoung PS, Tsui W, et al. Hypometabolism exceeds atrophy in presymptomatic early-onset familial Alzheimer's disease. J Nucl Med. 2006;47(11):1778-86.

22. Dash SK. Cognitive impairment and diabetes. Recent Pat Endocr Metab Immune Drug Discov. 2013;7(2):155-65. https://doi.org/10.2174/18722 14811307020009.

23. Grieb P. Intracerebroventricular streptozotocin injections as a model of Alzheimer's disease: in search of a relevant mechanism. Mol Neurobiol. 2016;53(3):1741-52. https://doi.org/10.1007/s12035-015-9132-3.

24. Leibson CL, Rocca WA, Hanson VA, Cha R, Kokmen E, O'brien PC, et al. Risk of dementia among persons with diabetes mellitus: a population-based cohort study. Am J Epidemiol. 1997;145(4):301-8. https://doi.org/10. 1093/oxfordjournals.aje.a009106.

25. Xu J, Begley P, Church SJ, Patassini S, Mcharg S, Kureishy N, et al. Elevation of brain glucose and polyol-pathway intermediates with accompanying brain-copper deficiency in patients with Alzheimer's disease: metabolic basis for dementia. Sci Rep. 2016;6:27524. https://doi.org/10.1038/srep2 7524.

26. Chen Y, Liang Z, Tian Z, Blanchard J, Dai CL, Chalbot S, et al. Intracerebroventricular streptozotocin exacerbates Alzheimer-like changes of 3xTg-AD mice. Mol Neurobiol. 2014;49(1):547-62. https://doi.org/10. 1007/s12035-013-8539-y.

27. Huang HJ, Chen SL, Chang YT, Chyuan JH, Hsieh-Li HM. Administration of Momordica charantia enhances the neuroprotection and reduces the side effects of $\mathrm{LiCl}$ in the treatment of Alzheimer's disease. Nutrients. 2018;10(12). https://doi.org/10.3390/nu10121888.

28. Huang HJ, Chen SL, Hsieh-Li HM. Administration of NaHS attenuates footshock-induced pathologies and emotional and cognitive dysfunction in triple transgenic Alzheimer's mice. Front Behav Neurosci. 2015;9:312. https://doi.org/10.3389/fnbeh.2015.00312.

29. Huang HJ, Huang HY, Hsieh-Li HM. MGCD0103, a selective histone deacetylase inhibitor, coameliorates oligomeric Abeta25-35-induced anxiety and cognitive deficits in a mouse model. CNS Neurosci Ther. 2019:25(2):175-86. https://doi.org/10.1111/cns.13029.

30. Garcia-Villalba R, Gimenez-Bastida JA, Garcia-Conesa MT, Tomas-Barberan FA, Carlos Espin J, Larrosa M. Alternative method for gas chromatographymass spectrometry analysis of short-chain fatty acids in faecal samples. J Sep Sci. 2012;35(15):1906-13. https://doi.org/10.1002/jssc.201101121.

31. Xu ZP, Gan GS, Liu YM, Xiao JS, Liu HX, Mei B, et al. Adiponectin attenuates streptozotocin-induced tau hyperphosphorylation and cognitive deficits by rescuing PI3K/Akt/GSK-3beta pathway. Neurochem Res. 2018;43(2):316-23. https://doi.org/10.1007/s11064-017-2426-2.

32. Essawy AE, Abdou HM, Ibrahim HM, Bouthahab NM. Soybean isoflavone ameliorates cognitive impairment, neuroinflammation, and amyloid $\beta$ accumulation in a rat model of Alzheimer's disease. Environ Sci Pollut Res. 2019. https://doi.org/10.1007/s11356-019-05862-z.

33. Gilbert BJ. The role of amyloid $\beta$ in the pathogenesis of Alzheimer's disease. J Clin Pathol. 2013;66(5):362. https://doi.org/10.1136/jclin path-2013-201515.

34. Yamamoto N, Fujii Y, Kasahara R, Tanida M, Ohora K, Ono Y, et al. Simvastatin and atorvastatin facilitates amyloid beta-protein degradation in extracellular spaces by increasing neprilysin secretion from astrocytes through activation of MAPK/Erk1/2 pathways. Glia. 2016;64(6):952-62. https://doi.org/10.1002/glia.22974.

35. Birch AM, Katsouri L, Sastre M. Modulation of inflammation in transgenic models of Alzheimer's disease. J Neuroinflammation. 2014;11:25. https:// doi.org/10.1186/1742-2094-11-25.

36. Wyss-Coray T. Inflammation in Alzheimer disease: driving force, bystander or beneficial response? Nat Med. 2006;12(9):1005-15. https://doi.org/10. 1038/nm1484.

37. Ju IG, Kim N, Choi JG, Lee JK, Oh MS. Cuscutae Japonicae semen ameliorates memory dysfunction by rescuing synaptic damage in Alzheimer's disease models. Nutrients. 2019;11(11). https://doi.org/10.3390/nu111 12591.

38. Nelson PT, Alafuzoff I, Bigio EH, Bouras C, Braak H, Cairns NJ, et al. Correlation of Alzheimer disease neuropathologic changes with cognitive status: a review of the literature. J Neuropathol Exp Neurol. 2012;71(5):362-81. https://doi.org/10.1097/NEN.0b013e31825018f7.

39. Mehla J, Pahuja M, Gupta YK. Streptozotocin-induced sporadic Alzheimer's disease: selection of appropriate dose. J Alzheimers Dis. 2013;33(1):17-21. https://doi.org/10.3233/JAD-2012-120958.

40. Salkovic-Petrisic M, Osmanovic J, Grünblatt E, Riederer P, Hoyer S. Modeling sporadic Alzheimer's disease: the insulin resistant brain state generates multiple long-term morphobiological abnormalities including hyperphosphorylated tau protein and amyloid-beta. J Alzheimers Dis. 2009;18(4):729-50. https://doi.org/10.3233/JAD-2009-1184.

41. Salkovic-Petrisic M, Knezovic A, Hoyer S, Riederer P. What have we learned from the streptozotocin-induced animal model of sporadic Alzheimer's disease, about the therapeutic strategies in Alzheimer's research. J Neural Transm (Vienna). 2013;120(1):233-52. https://doi.org/10.1007/ s00702-012-0877-9.

42. Jope RS, Yuskaitis CJ, Beurel E. Glycogen synthase kinase-3 (GSK3): inflammation, diseases, and therapeutics. Neurochem Res. 2007;32(4-5):577-95. https://doi.org/10.1007/s11064-006-9128-5.

43. Yang W, Ma J, Liu Z, Lu Y, Hu B, Yu H. Effect of naringenin on brain insulin signaling and cognitive functions in ICV-STZ induced dementia model of rats. Neurol Sci. 2014;35(5):741-51. https://doi.org/10.1007/ s10072-013-1594-3.

44. Ishiguro K, Shiratsuchi A, Sato S, Omori A, Arioka M, Kobayashi S, et al. Glycogen synthase kinase 3 beta is identical to tau protein kinase I generating several epitopes of paired helical filaments. FEBS Lett. 1993;325(3):167-72. https://doi.org/10.1016/0014-5793(93)81066-9.

45. Ly PT, Wu Y, Zou H, Wang R, Zhou W, Kinoshita A, et al. Inhibition of GSK3ß-mediated BACE1 expression reduces Alzheimer-associated phenotypes. J Clin Invest. 2013;123(1):224-35. https://doi.org/10.1172/JCl64 516.

46. Augustinack JC, Schneider A, Mandelkow EM, Hyman BT. Specific tau phosphorylation sites correlate with severity of neuronal cytopathology in Alzheimer's disease. Acta Neuropathol. 2002;103(1):26-35. https://doi. org/10.1007/s004010100423.

47. Luna-Munoz J, Garcia-Sierra F, Falcon V, Menendez I, Chavez-Macias L, Mena R. Regional conformational change involving phosphorylation of tau protein at the Thr231, precedes the structural change detected by Alz-50 antibody in Alzheimer's disease. J Alzheimers Dis. 2005;8(1):29-41. https://doi.org/10.3233/jad-2005-8104.

48. Lin YT, Cheng JT, Liang LC, Ko CY, Lo YK, Lu PJ. The binding and phosphorylation of Thr231 is critical for Tau's hyperphosphorylation and functional regulation by glycogen synthase kinase 3beta. J Neurochem. 2007;103(2):802-13. https://doi.org/10.1111/j.1471-4159.2007.04792.x.

49. Ly PT, Wu Y, Zou H, Wang R, Zhou W, Kinoshita A, et al. Inhibition of GSK3beta-mediated BACE1 expression reduces Alzheimer-associated phenotypes. J Clin Invest. 2013;123(1):224-35. https://doi.org/10.1172/ JCl64516.

50. Zhou D, Liu H, Li C, Wang F, Shi Y, Liu L, et al. Atorvastatin ameliorates cognitive impairment, Abeta1-42 production and Tau hyperphosphorylation in APP/PS1 transgenic mice. Metab Brain Dis. 2016;31(3):693-703. https:// doi.org/10.1007/s11011-016-9803-4.

51. Ahmad A, Ali T, Park HY, Badshah H, Rehman SU, Kim MO. Neuroprotective effect of fisetin against amyloid-beta-induced cognitive/synaptic dysfunction, neuroinflammation, and neurodegeneration in adult mice. Mol Neurobiol. 2017;54(3):2269-85. https://doi.org/10.1007/ s12035-016-9795-4

52. Craft JM, Watterson DM, Marks A, Van Eldik LJ. Enhanced susceptibility of S-100B transgenic mice to neuroinflammation and neuronal dysfunction induced by intracerebroventricular infusion of human beta-amyloid. Glia. 2005;51(3):209-16. https://doi.org/10.1002/glia.20194.

53. Oakley H, Cole SL, Logan S, Maus E, Shao P, Craft J, et al. Intraneuronal beta-amyloid aggregates, neurodegeneration, and neuron loss in transgenic mice with five familial Alzheimer's disease mutations: potential factors in amyloid plaque formation. J Neurosci. 2006;26(40):10129-40. https://doi.org/10.1523/JNEUROSCI.1202-06.2006.

54. Aliashrafi M, Nasehi M, Zarrindast M-R, Joghataei MT, Zali H, Siadat SD. Association of microbiota-derived propionic acid and Alzheimer's 
disease; bioinformatics analysis. J Diabetes Metab Disord. 2020. https:// doi.org/10.1007/s40200-020-00564-7.

55. Al-Lahham SH, Peppelenbosch MP, Roelofsen H, Vonk RJ, Venema K. Biological effects of propionic acid in humans; metabolism, potential applications and underlying mechanisms. Biochim Biophys Acta. 2010;1801(11):1175-83. https://doi.org/10.1016/j.bbalip.2010.07.007.

56. Lobzhanidze G, Lordkipanidze T, Zhvania M, Japaridze N, Macfabe DF, Pochkidze $\mathrm{N}$, et al. Effect of propionic acid on the morphology of the amygdala in adolescent male rats and their behavior. Micron. 2019;125:102732. https://doi.org/10.1016/j.micron.2019.102732.

57. Al-Owain M, Kaya N, Al-Shamrani H, Al-Bakheet A, Qari A, Al-Muaigl S, et al. Autism spectrum disorder in a child with propionic acidemia. JIMD Rep. 2013;7:63-6. https://doi.org/10.1007/8904_2012_143.

58. Macfabe DF. Short-chain fatty acid fermentation products of the gut microbiome: implications in autism spectrum disorders. Microb Ecol Health Dis. 2012;23. https://doi.org/10.3402/mehd.v23i0.19260.

59. Wajner M, Latini A, Wyse AT, Dutra-Filho CS. The role of oxidative damage in the neuropathology of organic acidurias: insights from animal studies. J Inherit Metab Dis. 2004;27(4):427-48. https://doi.org/10.1023/B:BOLI. 0000037353.13085.e2.

60. Lyness SA, Zarow C, Chui HC. Neuron loss in key cholinergic and aminergic nuclei in Alzheimer disease: a meta-analysis. Neurobiol Aging. 2003;24(1):1-23. https://doi.org/10.1016/s0197-4580(02)00057-X.

61. Selkoe DJ. Alzheimer's disease is a synaptic failure. Science. 2002;298(5594):789-91. https://doi.org/10.1126/science.1074069.

62. Liu YW, Liong MT, Chung YE, Huang HY, Peng WS, Cheng YF, et al. Effects of Lactobacillus plantarum PS128 on children with autism spectrum disorder in Taiwan: a randomized, double-blind, placebo-controlled trial. Nutrients. 2019;11(4). https://doi.org/10.3390/nu11040820.

63. Liao PL, Wu CC, Chen TY, Tsai YC, Peng WS, Yang DJ, et al. Toxicity studies of Lactobacillus plantarum PS128(TM) isolated from spontaneously fermented mustard greens. Foods. 2019;8(12). https://doi.org/10.3390/ foods 8120668.

64. Abraham D, Feher J, Scuderi GL, Szabo D, Dobolyi A, Cservenak M, et al. Exercise and probiotics attenuate the development of Alzheimer's disease in transgenic mice: role of microbiome. Exp Gerontol. 2019;115:12231. https://doi.org/10.1016/j.exger.2018.12.005.

65. Bonfili L, Cecarini V, Cuccioloni M, Angeletti M, Berardi S, Scarpona S, et al. SLAB51 probiotic formulation activates SIRT1 pathway promoting antioxidant and neuroprotective effects in an AD mouse model. Mol Neurobiol. 2018:55(10):7987-8000. https://doi.org/10.1007/s12035-018-0973-4.

66. Shukla PK, Delotterie DF, Xiao J, Pierre JF, Rao R, Mcdonald MP, et al. Alterations in the gut-microbial-inflammasome-brain axis in a mouse model of Alzheimer's disease. Cells. 2021;10(4). https://doi.org/10.3390/ cells 10040779.

67. Xu HM, Huang HL, Zhou YL, Zhao HL, Xu J, Shou DW, et al. Fecal microbiota transplantation: a new therapeutic attempt from the gut to the brain. Gastroenterol Res Pract. 2021;2021:6699268. https://doi.org/10. 1155/2021/6699268.

68. Liao JF, Cheng YF, You ST, Kuo WC, Huang CW, Chiou JJ, et al. Lactobacillus plantarum PS128 alleviates neurodegenerative progression in 1-methyl-4-phenyl-1,2,3,6-tetrahydropyridine-induced mouse models of Parkinson's disease. Brain Behav Immun. 2020;90:26-46. https://doi.org/ 10.1016/j.bbi.2020.07.036

69. Silva YP, Bernardi A, Frozza RL. The role of short-chain fatty acids from gut microbiota in gut-brain communication. Front Endocrinol (Lausanne). 2020;11:25. https://doi.org/10.3389/fendo.2020.00025.

70. Ho L, Ono K, Tsuji M, Mazzola P, Singh R, Pasinetti GM. Protective roles of intestinal microbiota derived short chain fatty acids in Alzheimer's disease-type beta-amyloid neuropathological mechanisms. Expert Rev Neurother. 2018;18(1):83-90. https://doi.org/10.1080/14737175.2018. 1400909.

71. Zhang L, Wang Y, Xiayu X, Shi C, Chen W, Song N, et al. Altered gut microbiota in a mouse model of Alzheimer's disease. J Alzheimers Dis. 2017;60(4):1241-57. https://doi.org/10.3233/JAD-170020.

72. Tirosh A, Calay ES, Tuncman G, Claiborn KC, Inouye KE, Eguchi K, et al. The short-chain fatty acid propionate increases glucagon and FABP4 production, impairing insulin action in mice and humans. Sci Transl Med. 2019;11(489). https://doi.org/10.1126/scitranslmed.aav0120.

73. Koh A, Molinaro A, Stahlman M, Khan MT, Schmidt C, Manneras-Holm L, et al. Microbially produced imidazole propionate impairs insulin signaling through mTORC1. Cell. 2018;175(4):947-961.e17. https://doi.org/10. 1016/j.cell.2018.09.055.

74. Karlsson FH, Tremaroli V, Nookaew I, Bergstrom G, Behre CJ, Fagerberg B, et al. Gut metagenome in European women with normal, impaired and diabetic glucose control. Nature. 2013;498(7452):99-103. https://doi.org/ 10.1038/nature12198.

75. Larsen N, Vogensen FK, Van Den Berg FW, Nielsen DS, Andreasen AS, Pedersen BK, et al. Gut microbiota in human adults with type 2 diabetes differs from non-diabetic adults. PLoS One. 2010;5(2):e9085. https://doi. org/10.1371/journal.pone.0009085.

76. Mepham JR, Boon FH, Foley KA, Cain DP, Macfabe DF, Ossenkopp KP. Impaired spatial cognition in adult rats treated with multiple intracerebroventricular (ICV) infusions of the enteric bacterial metabolite, propionic acid, and return to baseline after 1 week of no treatment: contribution to a rodent model of ASD. Neurotox Res. 2019;35(4):823-37. https://doi.org/10.1007/s12640-019-0002-z.

77. Mirza R, Sharma B. Selective modulator of peroxisome proliferatoractivated receptor-alpha protects propionic acid induced autism-like phenotypes in rats. Life Sci. 2018;214:106-17. https://doi.org/10.1016/j.lfs. 2018.10.045.

78. Karuri AR, Dobrowsky E, Tannock IF. Selective cellular acidification and toxicity of weak organic acids in an acidic microenvironment. $\mathrm{Br} J$ Cancer. 1993;68(6):1080-7. https://doi.org/10.1038/bjc.1993.485.

79. El-Ansary A, Bacha AB, Bjorklund G, Al-Orf N, Bhat RS, Moubayed N, et al. Probiotic treatment reduces the autistic-like excitation/inhibition imbalance in juvenile hamsters induced by orally administered propionic acid and clindamycin. Metab Brain Dis. 2018;33(4):1155-64. https://doi.org/10. 1007/s11011-018-0212-8.

80. Zhang ZH, Wen L, Wu QY, Chen C, Zheng R, Liu Q, et al. Long-term dietary supplementation with selenium-enriched yeast improves cognitive impairment, reverses synaptic deficits, and mitigates tau pathology in a triple transgenic mouse model of Alzheimer's disease. J Agric Food Chem. 2017;65(24):4970-9. https://doi.org/10.1021/acs.jafc.7b01465.

\section{Publisher's Note}

Springer Nature remains neutral with regard to jurisdictional claims in published maps and institutional affiliations.

Ready to submit your research? Choose BMC and benefit from:

- fast, convenient online submission

- thorough peer review by experienced researchers in your field

- rapid publication on acceptance

- support for research data, including large and complex data types

- gold Open Access which fosters wider collaboration and increased citations

- maximum visibility for your research: over 100M website views per year

At BMC, research is always in progress.

Learn more biomedcentral.com/submissions 